Document downloaded from:

http://hdl.handle.net/10251/141964

This paper must be cited as:

Sierra-Varela, LA.; Yepes, V.; García-Segura, T.; Pellicer, E. (03-2). Bayesian network method for decision-making about the social sustainability of infrastructure projects. Journal of Cleaner Production. 176:521-534. https://doi.org/10.1016/j.jclepro.2017.12.140

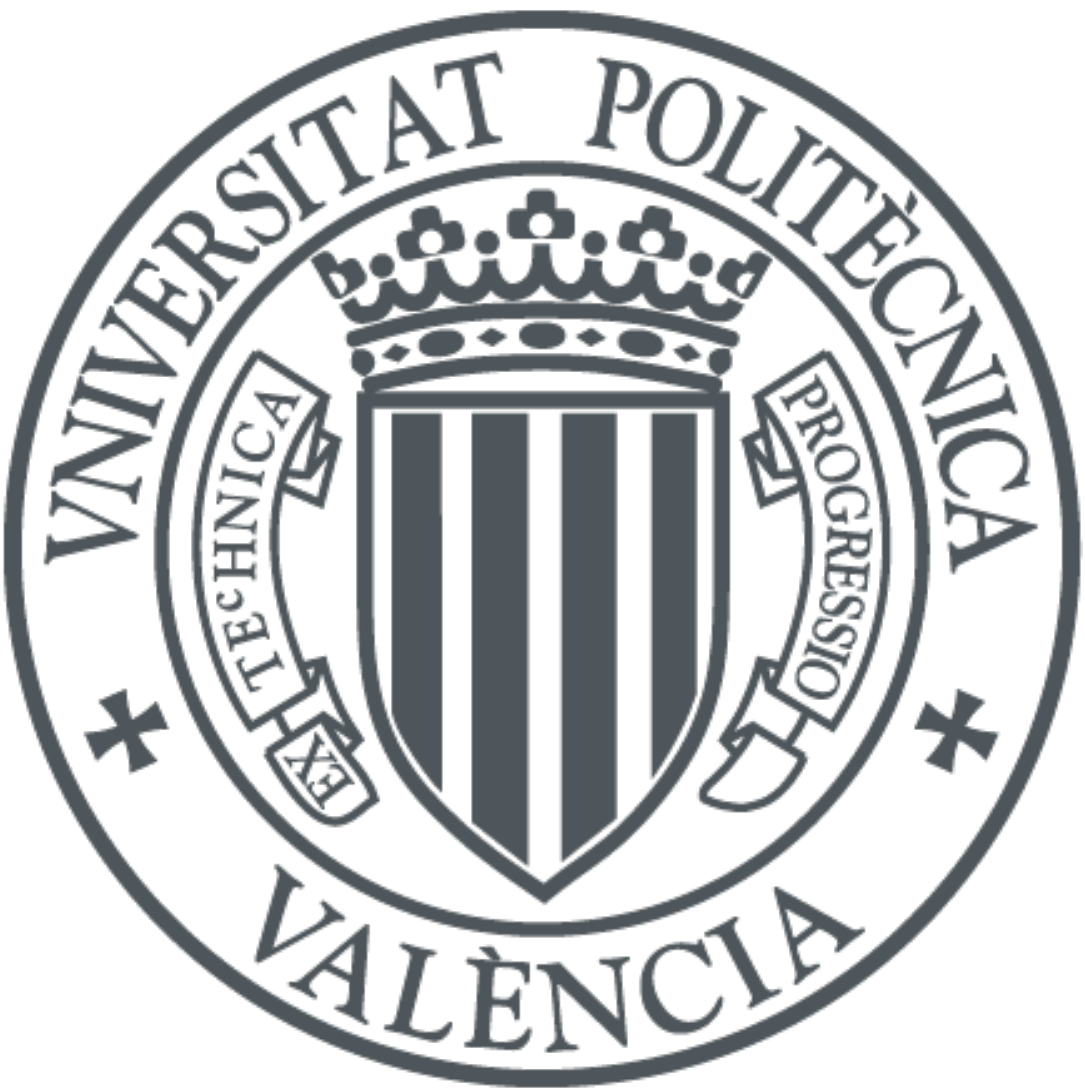

The final publication is available at

https://doi.org/10.1016/j.jclepro.2017.12.140

Copyright Elsevier

Additional Information 


\title{
BAYESIAN NETWORK METHOD FOR DECISION-MAKING ABOUT THE SOCIAL SUSTAINABILITY OF INFRASTRUCTURE PROJECTS
}

\author{
Leonardo A. Sierra \\ Instructor, Departamento de Ingeniería en Obras Civiles, Universidad de La Frontera, Francisco Salazar 01145, Temuco, \\ Chile, leonardo.sierra@ufrontera.cl \\ Víctor Yepes \\ Professor, ICITECH, Universitat Politècnica de València, Camino de Vera s/n, 46022 Valencia, Spain, vyepesp@upv.es \\ Tatiana García-Segura \\ Assistant Professor, ICITECH, Universitat Politècnica de València, Camino de Vera s/n, 46022 Valencia, Spain, \\ tagarse@,cam.upv.es \\ Eugenio Pellicer \\ Corresponding Author, Associate Professor, School of Civil Engineering, Universitat Politècnica de València, Camino de \\ Vera s/n, 46022 Valencia, Spain, pellicer@upv.es, phone \#+34.963.879.562m fax \#+34.963.877.569.
}

\begin{abstract}
Nowadays, sustainability assessment tends to focus on the biophysical and economic aspects of the built environment. The social aspects are generally overestimated during an infrastructure evaluation. This study proposes a method to optimize infrastructure projects by assessing their social contribution. This proposal takes into account the infrastructure's interactions with the local environment in terms of its potential contribution in the short and long term. The method is structured in three stages: (1) preparation of a decision-making model, (2) formulation of the model, and (3) implementation of the model through optimization of infrastructure projects from the social sustainability viewpoint. The theory of Bayesian reasoning and a harmony search optimization algorithm are used to carry out the research. The paper presents the application to a case study of a set of alternatives for road infrastructure projects in El Salvador. This approach creates a model of participative decisionmaking. The results show that the method can distinguish socially efficient alternatives from the short and long-term contributions. In addition, the results suggest that some variables are less sensitive to the short and long-term maximization, while others vary their values to improve one objective or the other. The findings are directly applied to a real case. The method can be employed in the infrastructure formulation and prioritization phases and complemented with economic and environmental sustainability assessments.
\end{abstract}

KEYWORDS: Bayesian networks; infrastructure; multiple criteria; optimization algorithm; social sustainability.

\section{INTRODUCTION.}

Sustainable development makes the economy, society and the environment compatible without jeopardizing either development or future generations (WCED, 1987). In the last 30 years of the $20^{\text {th }}$ century, the discussion centered on ecology. Only at the end of the century did the international community begin to understand the importance of enhancing human abilities (Colantonio, 2011). In particular, the evaluation of social sustainability has been intertwined with assessment methods to make sustainable development measurable (TorresMachi et al., 2015; Pellicer et al., 2016). Environmental assessments incorporate this condition; however, the social aspect is not taken sufficiently into account (Valdes-Vasquez and Klotz, 2013; Dendena and Corsi et al., 2015). In addition, social aspects have limitations 
to being evaluated in the same way as other sustainability dimensions. Social and cultural heterogeneity drives the divergence of measurement criteria (Vanclay, 2002; Colantonio, 2011). Moreover, the estimation of social sustainability also requires the assessment of qualitative aspects. Munda $(2004 ; 2006)$ explains that the social development to achieve sustainability must consider the ethical sense of equity in both resource and cost distribution. Moreover, this author suggests that it is not enough to consider a development model based on economic and industrialized growth.

Infrastructure projects promote economic well-being, and they may complement many social interventions as well. For example, early maintenance investments improve the social contribution of services that require infrastructures (Schwarz et al., 2016). Thus, a complete infrastructure life-cycle review is crucial to assessing the impacts (Sierra et al., 2016; Zastrow et al., 2017). However, the social characteristics of a project have a high degree of uncertainty (Delgado and Romero, 2016). This is especially noticeable in the early stages of a project's development, prior to its construction (Gervásio and Simoes da Silva, 2012; Mel et al., 2015). Furthermore, the social contribution of an infrastructure project depends heavily on its interaction with the contextual conditions (Mostafa and El-Gohary, 2014; Dendena and Corsi, 2015). Contextual conditions refer to the development level of an area, such as the level of employability, public transport services, health and education services, and so forth.

In professional practice, Cost-Benefit Analysis is one of the most traditional methods used to evaluate infrastructures. However, non-monetary social externalities are not sufficiently considered. Bueno et al. (2015) and Mostafa and El-Gohary (2014) argue that the method does not include the distribution of cost, benefit or participation in the evaluation process. Social Life Cycle Assessment is another methodological framework that is still at an early stage of development and requires databases or inventories (van Haaster et al., 2017). In this sense, Benoit and Norris et al. (2012) have proposed social hotspot databases, which express social risks per country and productive sector. These databases provide information only for a limited set of sectors and there is no evidence of their use in infrastructure projects (ChhipiriShrestha et al., 2015; van Haaster et al., 2017). By contrast, multicriteria decision-making methods are commonly used for assessing construction projects. Social Multicriteria Assessment is an alternative to represent a multidimensional and participatory evaluation of social aspects (Munda, 2004; 2006). Jato-Espino et al. (2014) and Soltani et al. (2015) present a review of both methodological and participatory approaches in the infrastructure multicriteria assessment. This method gives considerable flexibility to deal with interconnected aspects and complement other appropriate techniques to evaluate each social aspect. Some recent studies have presented methods to prioritize specific projects of sustainable infrastructures (Sierra et al., 2017a; 2017b). However, a methodology to generate socially sustainable alternatives in a macro-context still requires additional efforts.

Investment in public infrastructure should be justified by the social contribution in the short and long term. In a short-term approach, the early return of the social benefits of an infrastructure will only be possible in a developed geographical context (Gannon and Liu, 1997). By contrast, a long-term approach will promote the social development in those contexts lacking in opportunities. In order to clarify these two periods (short and long term), two real examples are used. First, the second Penang Bridge, with a length of $24 \mathrm{~km}$, connects Batu Kawan on mainland Malaysia to Batu Maung on Penang Island (Yadollahi et al., 2015); after commissioning (short-term) there was evidence of accident reduction and a reduced noise level in the area, which previously had high traffic congestion. In the long-term, there 
was an improvement in equity accessing and using city services, and the surrounding area flourished economically. Second, the Dam "Urra 1" (Egre and Senecal, 2003), which affects $350 \mathrm{~km}$ along the Sinú River in the northwestern part of Colombia, impacts a local area with low public investment. In the short term, there were impacts on the activities of the fishermen and ethnic conflicts; in the long term, quality of life improved in the area due to the increased private investment, leading to social segregation and a change in lifestyle and identity. It is likely that the short and long-term approaches will not be simultaneous; i.e., the projects that involve early efficiency do not necessarily benefit the population groups that require major development. Therefore, the distribution of public benefits should endeavor to achieve equality in society (Foth et al., 2013; Delgado and Romero, 2016). In light of this, governments must consider the initial local conditions that interact with the project's characteristics in the prioritization of infrastructure projects. Accordingly, it is necessary to identify a series of infrastructure project alternatives which have an early return on social well-being and create development opportunities (Foth et al., 2013).

The literature regarding the social sustainability of infrastructure projects is limited. ValdesVasquez and Klotz (2013) propose a range of aspects to consider during the planning of an infrastructure project: user-centered design, environmental safety elements, communication with stakeholders, and contextual conditions, among others. In global terms, social criteria have been more clearly defined since the 1990s; the most prevalent criteria are those proposed by Labuschagne et al. (2005) comprising a social sustainability framework. Furthermore, a criterion requires the determination of certain attributes of the infrastructure and its location context defined as decision variables (Gervásio and Simoes da Silva, 2012). In particular, the social contribution of a set of decision variables will depend on the type of infrastructure and the contextual condition.

Technically, the number of decision variables and evaluation criteria may be too high. The problem is daunting when there are several possible states for each variable and criterion. Given the computer time and resources required, a conventional multicriteria analysis by itself does not provide a solution to the problem domain. Using the techniques of Bayesian reasoning, experts can generate a decision-making model (Chen and Pollino, 2012; Mkrtchyan et al., 2016). Participatory approaches have already employed Bayesian networks in sustainable decisions-making (Bertone et al., 2016; Mkrtchyan et al., 2016). In addition, Bayesian statistics have demonstrated advantages over classical inference in the analysis of efficiency in the water sector in Portugal (Carvalho and Marquez, 2016).

This paper uses a model to represent the relations among the variables of the infrastructure and the location context, the evaluation criteria and the short and long-term social contribution (Gannon and Liu, 1997; Labuschagne et al., 2005; Foth et al., 2013). In particular, this study employs the potential of Bayesian networks to establish probabilistic relationships between the infrastructure characteristics and the criteria that contribute to short and long-term social sustainability. Used as a decision-making model, the network allows evaluation of the infrastructure based on its contribution to the social goal. The decisionmaking model is used to determine a number of alternatives for infrastructure projects (Chen and Pollino, 2012). Through optimization, decision-makers can concentrate on the best alternatives from the social sustainability viewpoint. These alternatives will be the most likely to satisfy social improvement in the short and long term. These considerations are the point of departure for this study. The research reported in this paper proposes a method to optimize infrastructure project alternatives by assessing their social contribution; this proposal takes 
into account the infrastructure's interactions with the local environment in terms of its potential contribution in the short and long term.

This paper is organized as follows: It begins with the introduction of the techniques of Bayesian reasoning. Then, there is a description of the proposed method in order to prepare the decision-making model, to evaluate its connections and to apply an optimization algorithm in the multiple-criteria model. The sequence of the Bayesian network development model is established through a case study. Finally, the conclusions of the paper are presented.

\section{BAYESIAN NETWORKS APPLIED TO DECISION-MAKING}

Bayesian networks are a well-established graphical representation for encoding conditional probabilistic relationships among uncertain variables using Bayes' theorem (Chen and Pollino, 2012). In the literature there are solutions to both environmental and territorial problems that use Bayesian networks to support the decision-making. Specifically, Lo et al. (2005) identify waste treatment options in terms of global warming potential due to greenhouse gas emissions in Taiwan. Bertone et al. (2016) uses this technique to assess water quality-related health risks associated with extreme weather events for reservoir management in large dams in Australia. Dorner et al. (2007) model a Bayesian network system to emulate the behavior of nonpoint source pollution through data obtained from agricultural operations in southern Ontario. In addition, Celio et al. (2014) integrate both quantitative and qualitative data in a Bayesian network to model land use decisions in a pre-Alpine area in Switzerland. Osama and Sayed (2017) use a Bayesian model to study both pedestrian and cycling accidents, taking into account the spatial effect of various zones in Vancouver. Fulford et al. (2015) propose a Bayesian spatial classification model to focus the governance decisionmaking that improves different aspects of well-being in coastal communities in the USA.

A model of multi-criteria decision-making based on a Bayesian network can include: (1) the decision variables that depend on the decision-makers; (2) the result variables that express the system's exit expectation; and (3) the interconnection variables between the decision and the result variables. The model is made up of a set of interconnected nodes that represent each variable and its relation. Each relation involves a probability distribution that identifies the decision-makers' experience (Mkrtchyan et al., 2016). Once the model is built, the Bayesian reasoning method can help identify the likely impact given a set of decision elements.

Thus, a directed acyclic graph represents the probabilistic dependencies and independencies between each node. At this point, Bayesian networks can define a factorization of joint probability distribution on the related nodes (Pearl, 2009). Certain conditional probability distributions can be approximated by a causal independence model. In this sense, one widely used technique is the "Noisy-OR" (Pearl, 2009; Mkrtchyan et al., 2016). Studies by Diez and Druzdel (2007) have demonstrated the effectiveness of this application even with nonBoolean variables. A Noisy-OR assumes that each cause (parent node) is capable in itself of causing an effect, and that this ability is not affected by the presence or absence of other active causes (Lemmer and Gossink, 2004). Thus, a conditional probability distribution is represented according to Eq. [1], in which $v_{0}$ and $v_{p}$ are the states of a child and parent node, respectively; and $p_{i}$ is the conditional probability of the effect of each state of a parent node $i$ on a child node 0 (Diez and Druzdel, 2007). 


$$
P\left(v_{0} \mid v_{P}\right)=1-\prod_{i}\left(1-p_{i}\right)
$$

Noisy-OR models can favorably reduce the quantification of the $p_{i}$ (Pearl, 2009, Mkrtchyan et al., 2016). For example, for the application of a Bayesian network the number of $p_{i}$ would correspond to $m^{n+1}$, with $n$ being the number of parent nodes and $m$ the number of states of each parent and child node. However, a Noisy-OR model only requires a number of $m^{2} \cdot n$ conditional probabilities to define the model. In this line, a Noisy-OR model is adequate for intuitive interpretation and estimation by experts of conditional probabilities tables (Mkrtchyan et al., 2016). On this point, a survey makes it possible to estimate a conditional probability value $p i$ after rounds of questions with feedback and a consensus.

A Noisy-OR model assumes that all causes (of an effect) are independent of each other. Thus, the Noisy-OR model is limited to the capture of notions as synergy or interference between the causes. Furthermore, the possible value of parent variables not explicitly represented is dismissed (Lemmer and Gossink, 2004). In this case, additional questions to the experts would be required, which would hinder obtaining the model and quantification of parameters. Recursive functions and leaky models can respond to these issues (Diez and Druzdel, 2007). However, formulation of functions with more than three causes is more complex, bordering on unapproachable.

\section{PROPOSED METHOD}

As stated earlier, this research paper proposes a method to optimize infrastructure projects assessing their social contribution; it takes into consideration the infrastructure's interactions with the local environment in terms of its potential social contribution in the short and long term. In order to achieve this goal, it uses four basic techniques:

1. Document review regarding regional infrastructure design standards as well as current projects in the region.

2. Delphi technique: experts (at least eight) are required with experience in the fields of public infrastructure and social development; the Delphi method is applied according to the guidelines of Hallowell and Gambatese (2010) in order to reach a consensus (further details of the application of this technique are provided in sub-section 3.1).

3. Bayesian reasoning and the Noisy-OR techniques (using the software Matlab R2015b 64 bit) to estimate the social contribution of each infrastructure project in the multi-criteria model.

4. Multi-objective harmony search algorithm (Garcia-Segura and Yepes, 2016) to determine the socially optimal infrastructure projects also using the software Matlab (R2015b 64 bit).

The proposed method is structured in three stages (see Fig. 1): (1) preparation of a decisionmaking model, (2) formulation of the model, and (3) implementation of the model through optimization of infrastructure projects from the social sustainability viewpoint. In the first stage, the variables, relations and occurrence probabilities must be established according to regional needs; the Delphi technique is applied here. On this point, an infrastructure project alternative is a combination of the states of the decision variables that contribute to social sustainability. The decision variables come from the contextual condition and from the infrastructure design and planning. In the second stage, the short and long-term social 
contribution assesses the alternatives using the Bayesian reasoning method. Finally, a set of infrastructure and contextual conditions is determined using the harmony search algorithm. The specific description of each of the stages is described sequentially in the following subsections.

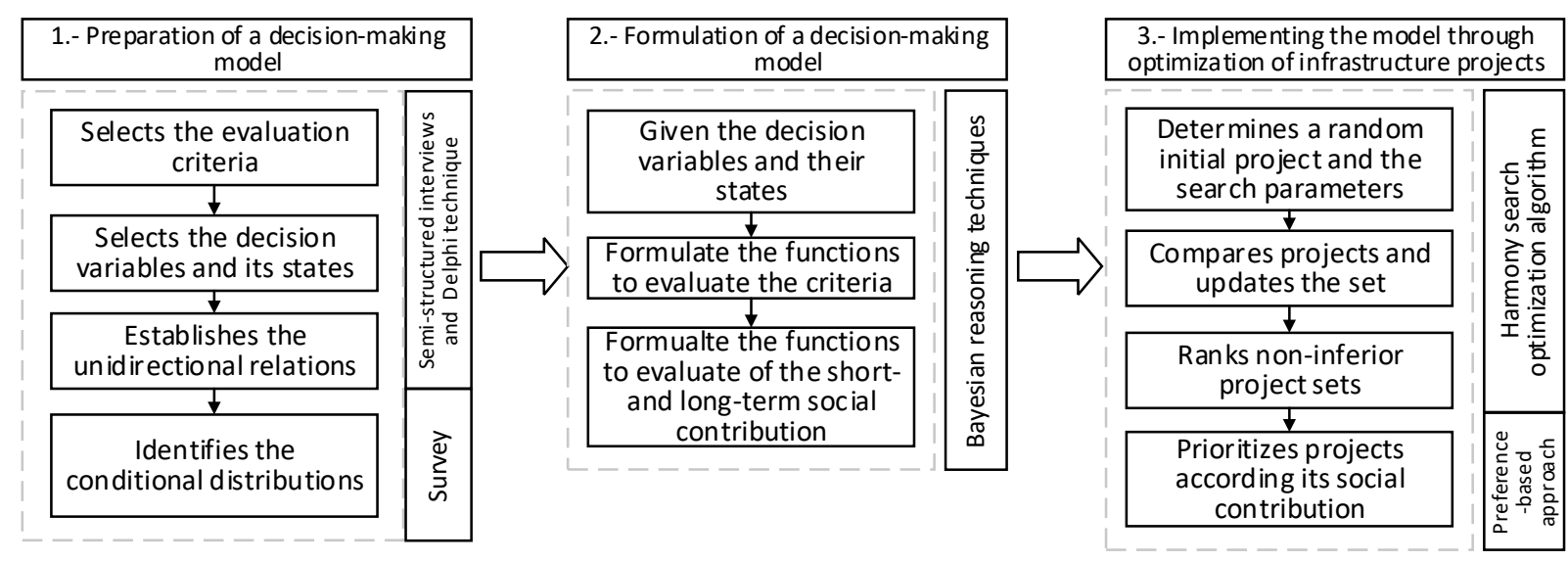

Fig.1. Stages of the proposed method.

\subsection{Preparation of the decision-making model (Stage 1)}

Preparation of the decision-making model requires that four elements affecting the decisionmaking be determined (see Fig. 1): (1) the social sustainability assessment criteria and their states; (2) the decision variables and the possible states that characterize an infrastructure project and its location context; (3) the unidirectional relations that identify the causality of the decision variables for each evaluation criterion; and (4) a conditional probability table for each relation in the network.

Determination of social sustainability assessment criteria in an infrastructure life cycle is currently not clearly defined (Valdés-Vásquez and Klotz, 2013; Pellicer et al., 2016; Zastrow et al., 2017). Therefore, a set of criteria must be established to measure the contribution of an infrastructure in the short and long term. For their part, the decision variables correspond to the aspects of the infrastructure project and its area of influence that affect the realization of an evaluation criterion. For each decision variable, the possible states of response must be identified. Indeed, certain decision variables and their states will depend on the type of infrastructure and the availability of information about the surroundings. In addition, determining the relations of the variables that affect each criterion and the criteria that affect the short and long-term social contribution defines all the causalities of the decision-making network.

Thus, in order to identify the criteria, the decision variables and their relations, a panel of experts is required to gain a consensus through the application of semi-structured interviews and the Delphi method (Hallowell and Gambatese, 2010; Cortes et al., 2010; Alshubbak et al., 2015). The Delphi method is a qualitative technique of structured communication developed as an interactive systematic method of prediction based on a panel of experts (Cortes et al., 2010; Alshubbak et al., 2015). Generally, the profile of the experts must fulfill the minimum requirements suggested by Hallowell and Gambatese (2010) in order to guarantee the rigor of 
the method. In particular, experience in the development of public infrastructure and institutional representation is required. Initially, a literature review (Labuschagne et al., 2005; Sierra et al., 2016) and the semi-structured interview with the experts will enable identification of a frame of reference for the criteria, decision variables and their states of action. From there, the process is carried out by asking the panel of experts to provide a solution to three consecutive questions, after consensus of the previous question:

Q.1.- According to the short and long-term social contribution for the region, assess the respective importance of each social evaluation criterion.

Q.2.- According to each social evaluation criterion for the region, assess the importance and applicability of the following decision variables of the infrastructure project and its area of influence.

Q.3.- According to each decision variable of the infrastructure project and its area of influence, identify whether you "agree" or "disagree" with the states that represent the levels of action and influence.

Consultation with the experts is formalized through three questionnaires (Q1, Q2 and Q3) containing a set of alternative responses to be assessed. Also, each expert can incorporate other alternatives that are not included. The consensus of Q1 allows the preparation and application of Q2; and the consensus of Q2 allows the application of Q3. Each item of Q1 and Q2 can be described on a scale of 1 (least importance/applicability) to 5 (greatest importance/applicability). Where there is consensus, the alternatives of greatest importance (described with 4 and 5) are selected. Otherwise, the distribution of the responses of each questionnaire is fed back to the panel for reconsideration and must continue until a consensus is reached. Q3 also requires the consensus of each state of decision variables. In this case each item in Q3 is described by the "agree" or "disagree". The specific sequence of steps for the Delphi method is illustrated in Fig. 2.

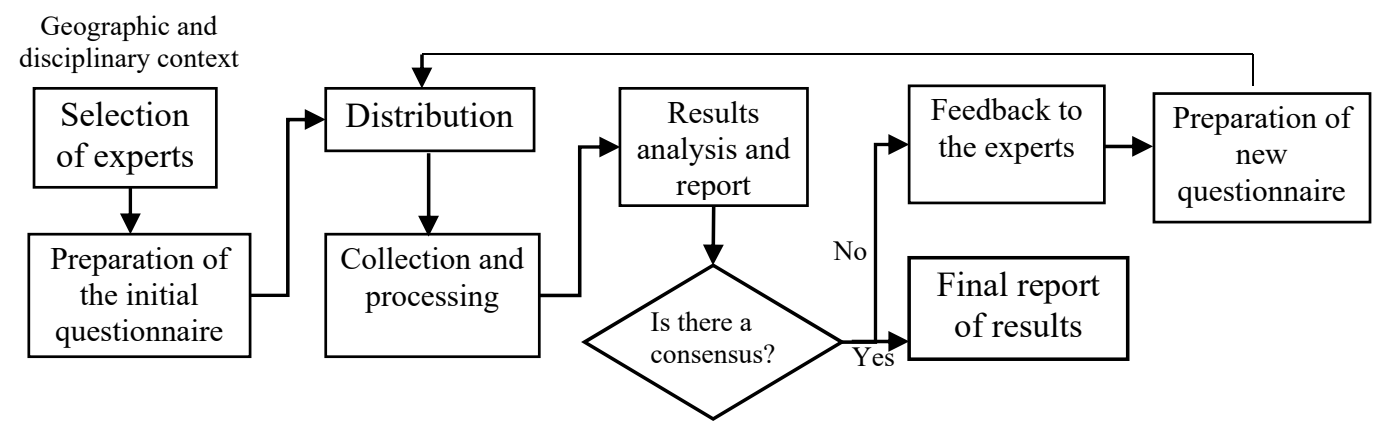

Fig. 2. Process for the identification of criteria, decision variables and their causal connection.

After structuring the Bayesian network, the next step is to configure the probabilistic relations through a conditional probability table for each relation. A conditional probability table is expressed in the form of a probability distribution that contains the statistical information of the decision-makers' experience (Mkrtchyan et al., 2016). As shown in Table 1, this is performed by administering a survey to the panel of experts, in which each identifies the probable distribution of impact of a child node as a result of each possible occurrence state of a parent node. The consultation is conducted according to the relevance of the profile with the 
extent of each relation. This means that the consultations with reference to the short and longterm levels of social contribution (represented by the nodes $S T$ and $L T$, respectively) with respect to a criterion (represented by node $C$ ) are aimed at institution representatives and opinion leaders. Conversely, the selection of the level of impact of the criteria (node $C$ ) with respect to the state of each decision variable (represented by node $D$ ) is an issue posed to the technical professionals in infrastructure development. Once the experts have been consulted, the selection is added and transferred to a conditional probability table. This aggregate part is the average of the distribution of each expert for each state of a parent node. Table 1 exemplifies the consultation with an expert, in which it has been noted that a reduction in travel time over $50 \%$ would have a high impact on accessibility to local health centers, whereas for other states of time reduction the impact would be low.

\begin{tabular}{|c|c|c|c|c|}
\hline \multicolumn{5}{|c|}{$\begin{array}{c}\text { For each state of "reduction in travel time" distribute } 100 \% \text { (or } 1 \text { ) } \\
\text { according the probable impact (high, medium, low) on the } \\
\text { "Accessibility to local health centers" }\end{array}$} \\
\hline & \multicolumn{4}{|c|}{ Child node (e.g. Accessibility to local health centers) } \\
\hline \multirow{5}{*}{ 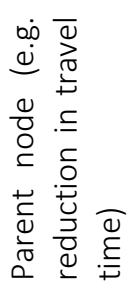 } & & High & Medium & Low \\
\hline & $\begin{array}{l}\text { More than } \\
50 \%\end{array}$ & 1 & 0 & 0 \\
\hline & {$[26 \%-50 \%]$} & 0.55 & 0.45 & 0 \\
\hline & {$[10 \%-25 \%]$} & 0 & 0.60 & 0.40 \\
\hline & $\begin{array}{l}\text { Less than } \\
10 \%\end{array}$ & 0 & 0.25 & 0.75 \\
\hline
\end{tabular}

Table 1. Selection of the level of impact of a child node with respect to the state of a parent node

\subsection{Formulation of the decision-making model (Stage 2)}

With the elements from stage 1, Bayesian reasoning can be applied to solve the decisionmaking problem. Fig. 3 illustrates a Bayesian network structure, where each of its nodes have been previously identified. The set of nodes is classified and defined corresponding to: (1) the decision variables $D_{N}$ (where $N=[1, \ldots n]$ represent the position of a decision variable), (2) evaluation criteria $C_{K}$ (where $K=[1, \ldots k]$ represent the position of a criterion), and (3) short and long-term social contribution, $S T-L T$ respectively. Also, the possible states of each node are represented according to the coding in small letters of the type of variable to which it is associated; for example: $d_{N 1}$ is the first state of the node $D_{N}, C_{K 1}$ is the first state of the node $C_{K}$ and, analogously, $s_{1}$ and $\mathrm{lt}_{1}$ are the first states of nodes $S T$ and $L T$, respectively. 


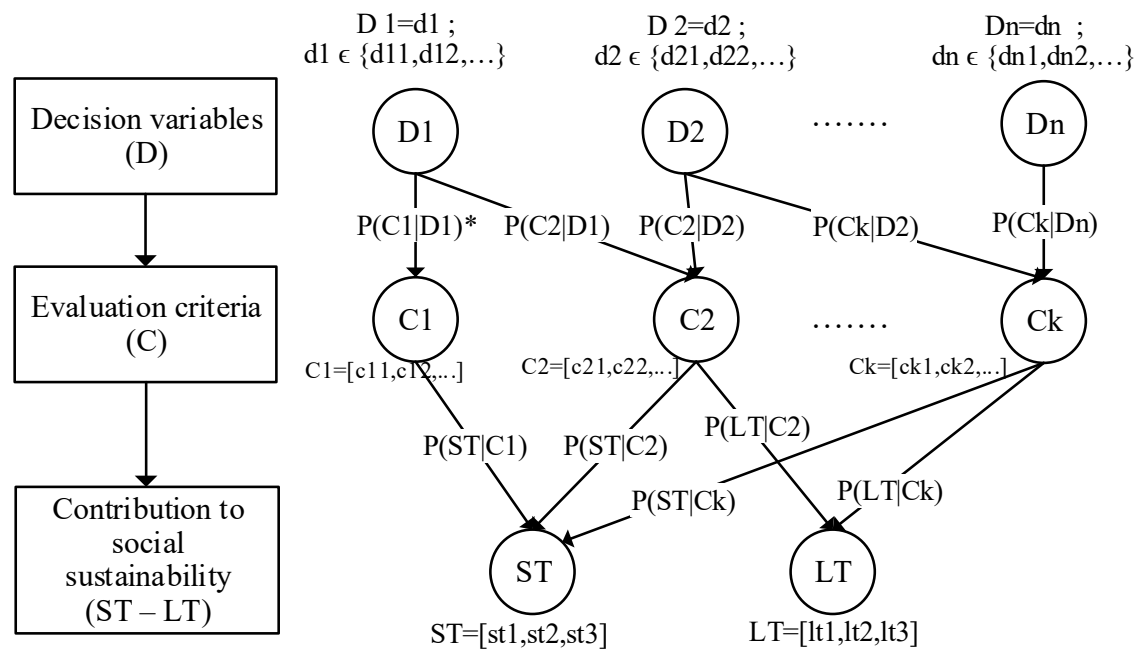

$\left.{ }^{*}\right) \mathrm{P}(\mathrm{C} 1 \mid \mathrm{D} 1)=$ Conditional probability of $\mathrm{C} 1$ respect to $\mathrm{D} 1$

Fig. 3. Multiple criteria decision-making model of $n$ decision variables, $k$ criteria and two joint probability variables $S T$ and $L T$.

After assigning a value set for the decision variables $\left(D_{1}=d_{1}, D_{2}=d_{2}, \ldots \ldots, D_{n}=d_{n}\right)$ that characterize an infrastructure project and its location context, Bayesian networks and a NoisyOR can be applied. With this the most probable values for the short and long-term social contribution can be deduced step-by-step in the direction of impact propagation. Thus, the conditional probabilities of the nodes $C_{2}$ and $L T$ can be determined specifically by Eqs. [2] and [3] in agreement with what is expressed by Eq. [1]. Through Eq. [4] it is expected that $L T$ will correspond to the specific state $I_{1}$ and Eq. [5] will determine the most probable level of social contribution for $L T$ according to the value of each state $a \in\{$ high, moderate, low $\}$. For qualitative states of high, moderate and low social contribution, these are associated with a score of 9, 5 and 1, respectively. Similarly, the probable level of social contribution for ST and for each criterion can be obtained.

$$
\begin{aligned}
& P\left(C_{2=} c_{21} \mid D_{1}=d_{1} ; D_{2}=d_{2}\right)=1-P\left(C_{2=} c_{21} \mid D_{1} \neq d_{1}\right) \cdot P\left(C_{2=} c_{21} \mid D_{2} \neq d_{2}\right) \\
& =1-\left[1-P\left(C_{2=} c_{21} \mid D_{1}=d_{1}\right)\right] \cdot\left[1-P\left(C_{2=} c_{21} \mid D_{2}=d_{2}\right)\right] \\
& P\left(L T=l t_{1} \mid C_{2}=c_{21} ; C_{k}=c_{k 1}\right)=1-P\left(L T=l t_{1} \mid C_{2} \neq c_{21}\right) \cdot P\left(L T=l t_{1} \mid C_{k} \neq c_{k 1}\right) \\
& =1-\left[1-P\left(L T=l t_{1} \mid C_{2}=c_{21}\right)\right] \cdot\left[1-P\left(L T=l t_{1} \mid C_{k}=c_{k 1}\right)\right] \\
& P\left(L T=l t_{1}\right)=\sum_{c_{2 i}} \sum_{c_{k t}} P\left(L T=l t_{1} \mid C_{2}=c_{2 i} ; C_{k}=c_{k t}\right) \\
& P(L T)=\sum_{a} l t_{a} \cdot P\left(L T=l t_{a}\right)
\end{aligned}
$$

These steps can determine the short and long-term social contribution value in one of each infrastructure project alternative in a specific location context. 


\subsection{Optimization of infrastructure projects (Stage 3)}

Optimal alternatives from the social sustainability viewpoint are determined based on the application of the harmony search optimization algorithm. The harmony search algorithm was proposed by Geem and Kim (2001) to find optimal alternatives based on the search for the perfect musical harmony. Then, Xu et al. (2010) proposed a multi-objective version of the HS algorithm. Ricart et al. (Ricart et al., 2011) studied two proposals of the multi-objective harmony search (MOHS) and compared them to a popular algorithm called the NSGA-II (non-dominated sorting genetic algorithm II). Results indicated that MOHS is competitive in comparison with NSGA-II. The algorithm is calibrated according to three parameters that determine the random selection, memory consideration and pitch adjustment. These are the harmony memory size (HMS), the harmony memory considering rate (HMCR) and the pitch adjusting rate (PAR). Additionally, the maximum number of improvisations without improvement (IWI) determines the stopping criterion. This paper uses the second proposal of Ricart et al. (2011) and adds a selection based on the crowding distance.

The algorithm begins by assigning the algorithm parameters. Secondly, a harmony memory matrix (HM) is filled with HMS vectors formed by random values. Each vector is a set of decision variables that displays a feasible alternative. Then, new harmony vectors are improvised following Eqs. [6] and [7]. The values of the decision variables are chosen from a set of possible states with the probability equal to (1-HMCR). Otherwise, the new alternative is chosen from the HM with a probability of HMCR. In this case, the value is modified one position up or down with a probability of PAR.

$$
\begin{aligned}
& X_{i}^{\prime} \in\left\{x_{i}^{1}, x_{i}^{2}, \ldots, x_{i}^{H M S}\right\} \text { with probability of } H M C R \\
& X_{i}^{\prime} \in X_{i} \text { with probability }(1-H M C R)
\end{aligned}
$$

After improvising HMS solutions, the HM is updated with the lowest ranking alternative. The ranking is determined according to the method illustrated by Garcia-Segura and Yepes (2016). The lowest-ranking alternatives are transferred to HM until the number of alternatives with the last ranking is larger than the space of HM. In this case, the alternatives with the highest crowding distance are chosen. The crowding distance metric improves the diversity of the alternatives. The procedure finishes when the number of sequential improvisations without improvement reaches IWI.

The application of this algorithm generates a set of optimal alternatives for a contribution to social sustainability in the short and long term. However, it is often difficult to decide on a large set of non-inferior alternatives (i.e., one in which an improvement in one goal requires degradation of another). Using a preference-based approach (Yepes et al., 2015), an equivalent preference can be assigned to the short and long-term social contribution. This enables a unique social contribution composite indicator to be established, which is the result of the arithmetic mean of the short and long-term states. Thus, the non-inferior alternatives can be prioritized according to the mean of their social contribution. 


\section{CASE STUDY}

The proposed method was applied to prioritize infrastructure projects according to their contribution to short and long-term social sustainability. Each project is defined by decision variables determined by the design, planning and location conditions. The case study is contextualized in the Eastern region of El Salvador, Central America. Decisions with regard to infrastructure investments in El Salvador are made mainly by the Ministry of Public Works and Transport, supported by the United Nations Development Program. Specifically, the case study focuses on four Departments. The backgrounds of each Department are specified in Fig. 4 .

\begin{tabular}{|c|c|c|c|c|c|c|c|}
\hline\{\}$_{5}^{2}$ & Department & IDH $^{1}$ & $\begin{array}{l}\text { GDP } \\
\text { (PPP) }^{3} \\
\text { US\$M }\end{array}$ & $\begin{array}{l}\text { Population } \\
2 \text { pop. }\end{array}$ & $\begin{array}{l}\text { Poverty } \\
\text { rate }^{2} \\
\%\end{array}$ & 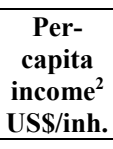 & $\begin{array}{c}\text { Illiteracy } \\
\text { rate }^{2} \\
\%\end{array}$ \\
\hline & La Unión & 0.598 & 1516823 & 263092 & 36.90 & 1422 & 21.89 \\
\hline & Usulután & 0.640 & 2097385 & 367871 & 38.40 & 1477 & 15.50 \\
\hline & Morazán & 0.594 & 999391 & 199021 & 48.06 & 1216 & 20.21 \\
\hline & San Miguel & 0.637 & 3101466 & 489546 & 34.45 & 1664 & 15.20 \\
\hline Adapted from Wikimedia Commons (2007) & Country & 0.672 & 45027182 & 6459911 & 34.84 & 1762 & 10.84 \\
\hline $\begin{array}{l}\text { Note: (1) IDH: Human Development Index; Human Develop } \\
\text { (2) Ministry of Economy, DYGESTIC (2015), Househ } \\
\text { (3) ) PPP: purchasing power parity; GDP: gross dom }\end{array}$ & $\begin{array}{l}\text { eeport - El S } \\
\text { rvey and mı } \\
\text { roduct; Hun }\end{array}$ & $\begin{array}{l}\text { or (UI } \\
\text { purnos }\end{array}$ & $\begin{array}{l}\text { 2013) } \\
\text { Report }\end{array}$ & . & & & \\
\hline
\end{tabular}

Fig. 4: Background of context of the case study

The projects involve opening or improving secondary roads in the study area. In addition, projects include roads that are currently made of gravel, have a high deterioration in paving, or are non-existent; however, their improvement is necessary and also technically feasible. Every intervention involves hydraulic concrete paving. As needed, this solution also incorporates the treatment of critical points and improvement of the drainage system. In this case the operating speed does not have to exceed $75 \mathrm{~km} / \mathrm{h}$. Other specific improvements depend on the area location.

\subsection{Preparation of the decision-making model for the case study}

Based on experience, knowledge and availability, a sample of 31 experts was selected. The competencies of the experts focused on transport infrastructure development and the application of public policies. Table 2 identifies the background of the selected experts.

Table 2: Background of selected experts

\begin{tabular}{|c|c|c|c|}
\hline Requirements & $\%$ full expert panel & $\begin{array}{c}\text { Group A } \\
(32.3 \%)\end{array}$ & $\begin{array}{c}\text { Group B } \\
(67.7 \%)\end{array}$ \\
\hline $\mathbf{A}$ & $25.8 \%$ & $30.0 \%$ & $23.8 \%$ \\
\hline B & $41.9 \%$ & $70.0 \%$ & $28.6 \%$ \\
\hline C & $41.9 \%$ & $100.0 \%$ & $14.3 \%$ \\
\hline \multirow[t]{3}{*}{ D } & {$[10-15]=$} & $40.0 \%$ & $33.3 \%$ \\
\hline & {$[15-20]=16.1 \%$} & $20.0 \%$ & $14.3 \%$ \\
\hline & {$[>20]=48.4 \%$} & $40.0 \%$ & $52.4 \%$ \\
\hline
\end{tabular}




\begin{tabular}{|c|c|c|c|c|}
\hline Requirements & $\%$ full e & xpert panel & $\begin{array}{c}\text { Group A } \\
(32.3 \%)\end{array}$ & $\begin{array}{c}\text { Group B } \\
(67.7 \%)\end{array}$ \\
\hline $\mathbf{E}$ & $19.4 \%$ & & $40.0 \%$ & $9.52 \%$ \\
\hline $\mathbf{F}$ & BS & $61.3 \%$ & $30.0 \%$ & $76.2 \%$ \\
\hline & MSc & $32.3 \%$ & $50.0 \%$ & $23.8 \%$ \\
\hline & $\mathrm{PhD}$ & $6.45 \%$ & $20.0 \%$ & -- \\
\hline $\mathbf{G}$ & $70.1 \%$ & & $70.0 \%$ & $71.4 \%$ \\
\hline \multicolumn{5}{|l|}{ Notes: } \\
\hline \multicolumn{5}{|c|}{ A: Primary or secondary author of at least 3 peer-reviewed journal articles } \\
\hline \multicolumn{5}{|c|}{ B: Invited to speak at a conference } \\
\hline \multicolumn{5}{|c|}{ C: Member or chair of a nationally recognized committee } \\
\hline \multicolumn{5}{|c|}{ D: At least 10 years of professional expertise } \\
\hline \multicolumn{5}{|c|}{ E: Faculty member at an accredited institution of higher learning } \\
\hline \multicolumn{5}{|c|}{ F: Advanced degree related to their field of work (minimum BS) } \\
\hline \multicolumn{5}{|c|}{$\mathrm{G}$ : Professional registration } \\
\hline \multicolumn{5}{|c|}{ Group A: Experience and training in public policy and social development } \\
\hline
\end{tabular}

According to the procedure described in Section 3.1, Fig. 5 represents the steps for the implementation of Stage 1. In steps 1, 2, 4 and 6 a literature review and semi-structured interviews were conducted to establish a frame of reference for the criteria, decision variables and their states. Q1, Q2 and Q3 are designed from the initial criteria for each short and longterm contribution, the decision variables related to the criteria, and the initial states for each decision variable, respectively. In steps 3, 5 and 7 the experts in Group A answered Q1 and then the experts in Group B answered Q2 and Q3, in each case with a consensus on the answers to the previous questionnaire. The consensus on each questionnaire was achieved through the Delphi method according to the process shown in Fig. 2. In this case, in steps 3 and 5 (Q1 and Q2), two rounds were required. In step 7 (Q3) the consensus was achieved in three rounds. The selected criteria (C), decision variables (D) and their codes are represented in Fig. 6. Regarding steps 5 and 7, the experts modified some aspects. For example, the decision variable "life expectancy in the area" was changed to "population attended by health professional (D3)" because it is a more appropriate indicator for local areas. In addition, experts pointed out contextual conditions that redefined states of decision variables. For instance, lack of rural access to the Internet as a means for participation (D8) meant that faceto-face meetings had greater importance. Frequency of public transportation (D1) was another case that needed adjustments. In the first round of Q1 and Q2, experts agreed on the social utility of road infrastructure projects; nevertheless, members of group A were mainly confused when specifying the criteria and variables of social impact. According to one comment, "These are not recurring themes to be determined as part of the country's practice of project planning" After comparing the initial results and orienting the criteria and decision variables, an agreement was reached, since the criteria and decision variables presented an importance level of 4 or 5 . In this case study, with an agreement over $75 \%, 13$ criteria (Q1) and 21 decision variables (Q2) were selected. Fig. 7 presents the final variation of the importance of selected decision variables for each criterion (step 5, Q2). In this case, the selected evaluation criteria are considered with an equivalent weight, since in a democratic social context with different interests of stakeholders it is not recommend ethically to assign more importance to some social criteria over others (Munda 2004, 2006). In Q3 some states of the decision variables $(D 3, D 5, D 6, D 12, D 20)$ required a third round to specify local impact levels. The consensus on the states of decision variables was confirmed by a non-parametric binomial test. The last two columns of Table 3 specify the agreement ratio and the p-value after the consensus.

A decision-making model, as shown in Fig. 6, was established at the end of step 7. The model identifies the incidence relations on the evaluation criteria and the short and long-term social contribution goals. For example, in this case accessibility to a health center can be influenced 
by such decision-making variables as the existence of public transport (D1), the reduction in travel time (D2) or zonal population attended by a health professional (D3). In addition, the figure shows which evaluation criteria affect the social contribution goals. A short-term social contribution depends on those criteria that can be achieved during the infrastructure design, construction or start-up. Thus, community involvement, the immediate contribution to road safety, the integration of the mobility service, the participation of stakeholders, the right of property and accessibility to health centers, schools and businesses are criteria that would be made clear early on. On the other hand, a long-term contribution depends on the assessment of criteria that would be made clear after the development of certain social skills. These criteria require a future visualization according to the zonal guidelines and the contribution of the road infrastructure. In this context, reduction of the accident rate, community identity and improvement of health and education, and local employability are criteria with a future projection for this case study. 


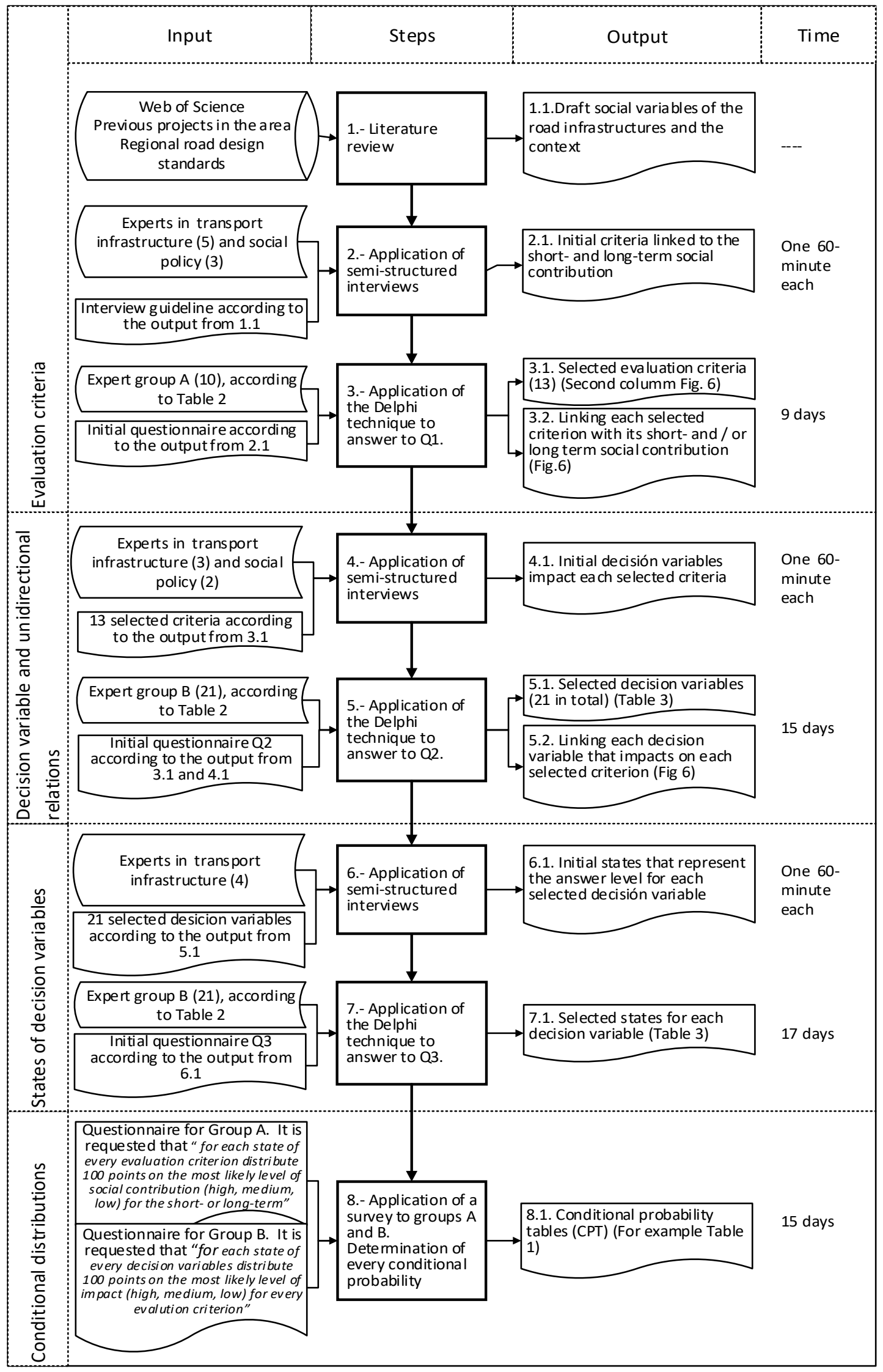

Fig. 5: Steps for the preparation of decision-making model 


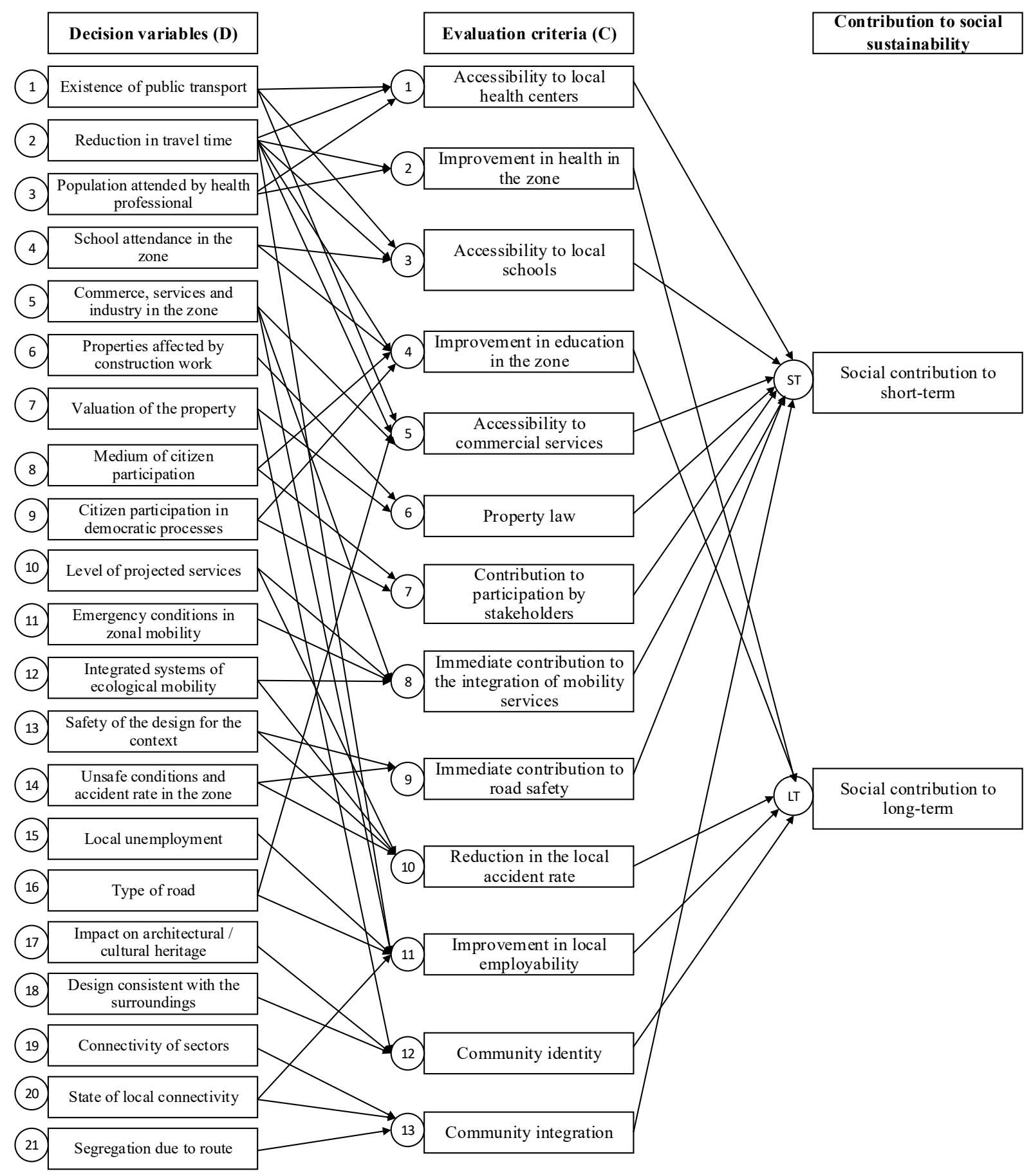

Fig. 6. Decision-making model for the case study 


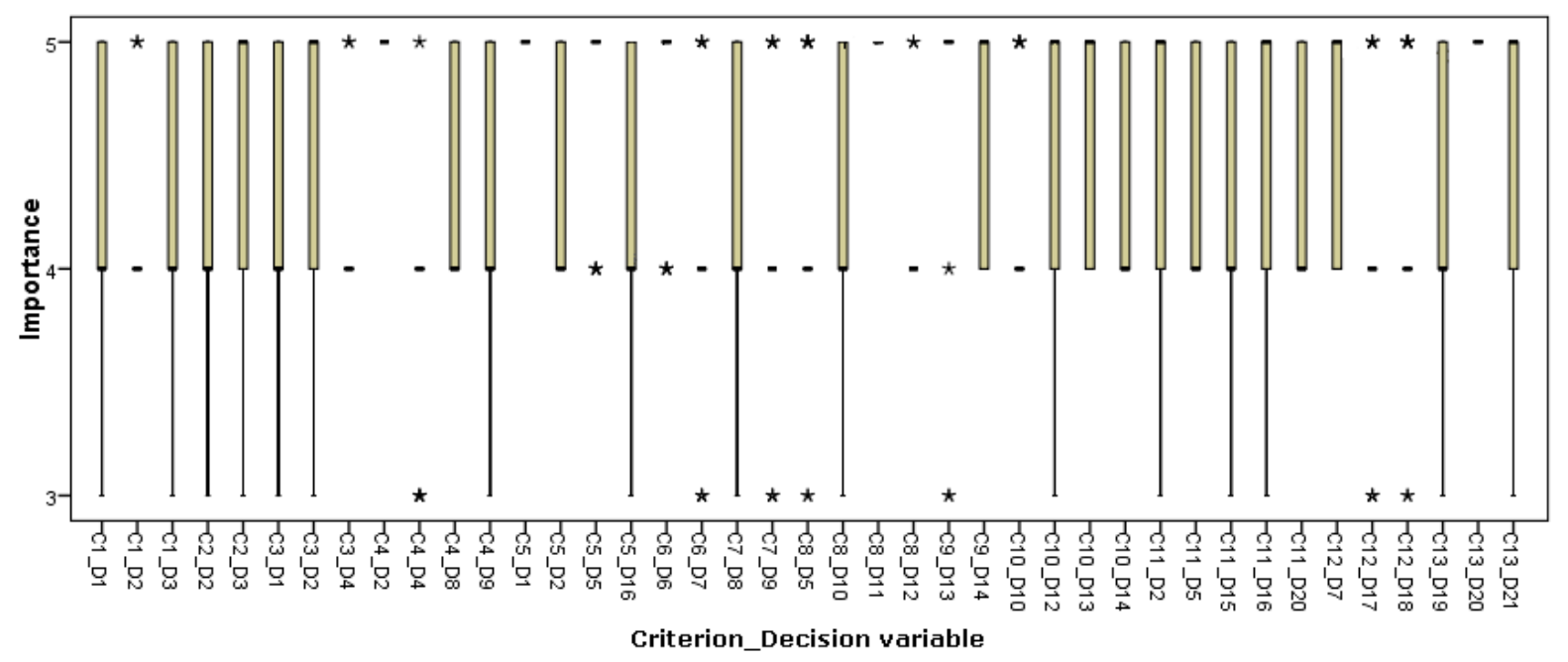

Fig. 7: Variation of the importance of the decision variables after the application of second round of Delphi method to Q2

Table 3: Decision variables of the road project and context that contribute to social sustainability.

\begin{tabular}{|c|c|c|c|c|c|}
\hline \multicolumn{2}{|c|}{ Decision variable } & \multirow{2}{*}{$\begin{array}{c}\text { Type }^{1} \\
\text { C }\end{array}$} & \multirow{2}{*}{$\begin{array}{l}\text { Decision variable states } \\
\text { 1) Frequent (more than two round trips per day), 2) Scarce (two or } \\
\text { fewer round trips per day), 3) Null }\end{array}$} & \multirow{2}{*}{$\begin{array}{l}\text { Ratio }^{2} \\
1.00\end{array}$} & \multirow{2}{*}{$\begin{array}{l}\text { p- } \\
\text { value. }^{3} \\
.002\end{array}$} \\
\hline & $\begin{array}{l}\text { Existence of public } \\
\text { transport }\end{array}$ & & & & \\
\hline $\mathrm{D} 2$ & Reduction in travel time & DP & 1) Less than $10 \%, 2)[10-25 \%], 3)[26-50 \%], 4)$ More than $50 \%$ & 0.95 & .019 \\
\hline D3 & $\begin{array}{l}\text { Population attended by } \\
\text { health professional }\end{array}$ & $\mathrm{C}$ & $\begin{array}{l}\text { 1) High: }>60 \%, 2 \text { ) Moderate: }[30-60 \%], 3) \text { Low: }<30 \% \text { of the population } \\
\text { affected by a health problem }\end{array}$ & 0.95 & .019 \\
\hline D4 & $\begin{array}{l}\text { School attendance in the } \\
\text { zone }\end{array}$ & $\mathrm{C}$ & $\begin{array}{l}\text { 1) High: }>80 \%, 2) \text { Moderate: }[40-80 \%], 3) \text { Low: }<40 \% \text { of the annual } \\
\text { enrollment rate }\end{array}$ & 0.90 & .000 \\
\hline D5 & $\begin{array}{l}\text { Commerce, services and } \\
\text { industry in the zone }\end{array}$ & $\mathrm{C}$ & $\begin{array}{l}\text { SI: Sales index (difference of the percentage of companies with increase } \\
\text { and reduction in annual economic activity): 1) High: } \mathrm{SI}>30,2 \text { ) } \\
\text { Moderate: } \mathrm{SI}=[15-30] ; 3) \text { Reduced: } \mathrm{SI}=[1-15] \text {; } 4 \text { ) Non-existent or } \\
\text { limited: } \mathrm{SI}<1.0\end{array}$ & 0.86 & .000 \\
\hline & Affected real estate & DP & $\begin{array}{l}\text { 1) Less than } 5,2)[5-20], 3)[21-50], 4) \text { More than } 50 \text { properties } \\
\text { This considers an influence area } 250 \mathrm{~m} \text { wide from the axis of the road } \\
\text { stretch }\end{array}$ & 0.90 & .000 \\
\hline & $\begin{array}{l}\text { Valuation of the } \\
\text { affected real estate }\end{array}$ & $\mathrm{C}$ & 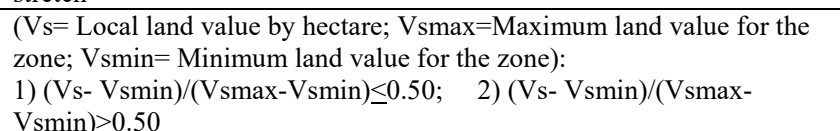 & 0.95 & .019 \\
\hline & $\begin{array}{l}\text { Medium of citizen } \\
\text { participation }\end{array}$ & DP & $\begin{array}{l}\text { 1) Mass media (radio, TV, print media); 2) Virtual media (web, e-mail); } \\
\text { 3) Face-to-face (meetings, interviews) }\end{array}$ & 0.90 & .000 \\
\hline D9 & $\begin{array}{l}\text { Citizen participation in } \\
\text { democratic processes. }\end{array}$ & $\mathrm{C}$ & $\begin{array}{l}\text { RCI: Rate of community involvement (number of people registered on } \\
\text { councils or municipal or neighborhood committees divided by the local } \\
\text { active population): } 1 \text { ) } \mathrm{RCI}<0.20 \text {; } 2 \text { RCI }=[0.20-0.35] \text {; 3) RCI }=[0.35- \\
0.50] \text {; 4) RCI }>0.50\end{array}$ & 0.95 & .019 \\
\hline & $\begin{array}{l}\text { Level of projected } \\
\text { mobility services }\end{array}$ & DP & $\begin{array}{l}\text { Mobility services envisaged as required in each case: a) Capacity of the } \\
\text { road to cover the projected traffic } 20 \text { years; b) Equipment and } \\
\text { infrastructure for integration in the context (footbridges, bus stops, } \\
\text { underpasses) } \\
\text { 1) Comply; 2) Do not comply with necessary requirements }\end{array}$ & 1.00 & .002 \\
\hline & $\begin{array}{l}\text { Emergency conditions } \\
\text { in zonal mobility }\end{array}$ & $\mathrm{C}$ & $\begin{array}{l}\text { 1) Geographic isolation: there is a single interrupted access; 2) Risky } \\
\text { access: access risky due to state of the road; 3) Risk conditions do not } \\
\text { apply }\end{array}$ & 0.90 & .000 \\
\hline D12 & $\begin{array}{l}\text { Integrated systems of } \\
\text { ecological mobility }\end{array}$ & DP & $\begin{array}{l}\text { 1) Promotes only motorized transport; 2) Promotes motorized, } \\
\text { pedestrian transport and/or bicycle paths }\end{array}$ & 0.95 & .019 \\
\hline & $\begin{array}{l}\text { Safety of the design for } \\
\text { the context }\end{array}$ & DP & $\begin{array}{l}\text { 1) Fully complies: } 100 \% \text { of the design elements fulfill the safety } \\
\text { requirements of the context; 2) Partially complies: with more than } 50 \% \\
\text { of the design elements account for safety in the context but not totally; } \\
\text { 3) Does not comply: none of the above }\end{array}$ & 1.00 & .002 \\
\hline D14 & Unsafe conditions and & $\mathrm{C}$ & 1) High: $>20$ deaths/100000 inhabs. year, due to unsafe conditions & 0.95 & .019 \\
\hline
\end{tabular}




\begin{tabular}{|c|c|c|c|c|}
\hline Decision variable & Type $^{1}$ & Decision variable states & Ratio $^{2}$ & \\
\hline accident rate of the zone & & $\begin{array}{l}\text { along the route; 2) Medium: } 10-20 \text { deaths/100,000 inhabs per year; } \\
\text { 3) Low: in other cases }\end{array}$ & & \\
\hline D15 $\quad$ Local unemployment & $\mathrm{C}$ & $\begin{array}{l}\text { 1) High, }>8.5 \% \text {; 2) Moderate: }[8.5-7.0 \%] ; 3) \text { Low: }<7.0 \% \\
\text { unemployment rate }\end{array}$ & 0.95 & .019 \\
\hline D16 Type of road & DP & $\begin{array}{l}\text { 1) Tertiary road; 2) Intermediate between secondary roads; } 3 \text { ) } \\
\text { Communicates directly to primary road }\end{array}$ & 0.95 & .019 \\
\hline $\begin{array}{l}\text { D17 Impact on architectural / } \\
\text { cultural heritage }\end{array}$ & C-DP & $\begin{array}{l}\text { 1) Temporary (it affects an item for a limited period after which returns } \\
\text { to its normal condition without external intervention); 2) Recoverable } \\
\text { or mitigable (the condition of the affected items recovered or reduced } \\
\text { through an external intervention); 3) Irrecoverable/the normal condition } \\
\text { of the affected items may not be recovered or reduced) }\end{array}$ & 0.95 & .019 \\
\hline $\begin{array}{l}\text { D18 Design consistent with } \\
\text { the environment and } \\
\text { social context }\end{array}$ & DP & $\begin{array}{l}\text { Design consistency implies characteristics of the infrastructure that } \\
\text { aligns with the culture of the context, the colors and/or shapes of the } \\
\text { ecosystem } \\
\text { 1) Partially (between } 25 \text { and } 50 \% \text { of equipment); 2) Mainly (more than } \\
50 \% \text { of equipment); 3) Not considered }\end{array}$ & 0.95 & .000 \\
\hline D19 Connectivity of sectors & DP & 1) Minor: $<5$ sectors; 2) Moderate: [5-15]; 3) High: $>15$ sectors & 0.95 & .019 \\
\hline $\begin{array}{l}\text { D20 State of local } \\
\text { connectivity }\end{array}$ & $\mathrm{C}$ & $\begin{array}{l}\text { 1) Pre-existing communication with large cities with populations of low- } \\
\text { density; 2) Pre-existing communication between populations of low- } \\
\text { density; 3) No communication with other urban centers with more } \\
\text { services }\end{array}$ & 0.95 & .019 \\
\hline D21 Segregation due to route & DP & $\begin{array}{l}\text { 1) Segregates without mitigation; 2) Segregates with mitigation; 3) } \\
\text { Does not cause segregation }\end{array}$ & 1.00 & .002 \\
\hline $\begin{array}{l}\text { (1) C: Variable coming from con } \\
\text { (2) Acceptance ratio "Agree" of } \\
\text { (3) Significance exact (unilateral }\end{array}$ & $\begin{array}{l}\text { loca } \\
\text { es of }\end{array}$ & $\begin{array}{l}\text { on ; DP: Variable coming from design and planning of road projects } \\
\text { sion variable } \\
l \text { Test at } 0.75 \text { for the states of the decision variables }\end{array}$ & & \\
\hline
\end{tabular}

After structuring the decision-making model, the conditional probability table for each relation was configured (see step 8 of Fig. 5). This way, the experts in Group A were consulted about the short and long-term social contribution (high, moderate, or low) of every impact (high, moderate and low) of linked criteria. For their part, Group B was asked about the impact (high, moderate, low) on each criterion due to the presence of every state of the corresponding decision variables. On a scale from 0 (minimum impact) to 1 (maximum impact), the experts had to distribute the impact degree. Thus, Table 4 exemplifies the response of an expert, who considered that a moderate level of school attendance influences $0.15,0.50$ and 0.35 the high, medium and low accessibility to the local school, respectively. The average of each of the experts' distributions determined each conditional probability table. Additionally, a decision variable can be grounds for two or more criteria with equal or opposite impact levels. For example, taking as a reference the relation from Fig. 7 and data obtained from Table 4, the pre-existence of a high rate of school attendance in the zone (node D4) favors the infrastructure social short-term contribution to the accessibility to local schools (node C3). Otherwise, given the existence of school-age children, a low rate of school attendance (node D4) demonstrates the contribution of an infrastructure project to a potential long-term improvement in education. The pre-existence of a favorable rate of school attendance (node $D 4$ ) does not guarantee a contribution to the improvement in the education of the zone (node $C 4$ ).

Table 4: Conditional probability of "Accessibility to schools" and "Improvement in education" with respect to "School attendance"

\begin{tabular}{|l|c|c|c|c|c|c|}
\hline \multirow{2}{*}{$\begin{array}{l}\text { D4.-School } \\
\text { attendance }\end{array}$} & \multicolumn{3}{|c|}{$\begin{array}{c}\text { C3.- Accessibility to local } \\
\text { schools }\end{array}$} & \multicolumn{3}{c|}{$\begin{array}{c}\text { C4.- } \\
\text { education in the zone }\end{array}$} \\
\cline { 2 - 7 } & High & Medium & Low & High & Medium & Low \\
\hline 1.- High & 0.76 & 0.17 & 0.07 & 0.00 & 0.20 & 0.80 \\
\hline 2.- Moderate & 0.15 & 0.50 & 0.35 & 0.40 & 0.50 & 0.10 \\
\hline
\end{tabular}




\subsection{Formulation of the decision-making model for the case study

\begin{tabular}{|l|l|l|l|l|l|l|}
\hline 3.- Low & 0.05 & 0.30 & 0.65 & 0.95 & 0.05 & 0.00 \\
\hline
\end{tabular}

Stage 2 of the method was developed according to the guidelines in section 3.2. The technique of Bayesian reasoning and the Noisy-OR were applied to the model. The code sets a function that determines the levels of short and long-term social contribution on a scale of 1 (low contribution) to 9 (high contribution). The model was formulated in three steps that determine: (1) the impact of the decision variables on the evaluation criteria; (2) the impact of the evaluation criteria on social contributions; and (3) the level of social contribution to the short and long-term. Steps 1 and 2 were coded according to the guidelines of Eqs. [2] and [3] respectively. Step 3 required Eq. [4] to estimate the probability of high, medium or low impact on each social contribution. Finally, social contribution levels were inferred from Eq. [5] and high (9), medium (5) and low (1) scores. The code was written using Matlab (R2015b 64 bit) language due to its flexibility and capacity in the development of algorithms.

\subsection{Optimization of road projects}

In this case Stage 3 of the method optimized the model using Matlab language (R2015b 64 bit). Considering 21 decision variables and each of their possible states (Table 3), the number of possible road projects (or combinations of decision variable states) exceeded $7.427 \mathrm{e}^{21}$ theoretical projects. Consequently, it would be difficult for the decision-maker to determine a reasonable set of alternatives with the best contribution to short and long-term social sustainability simultaneously. This way, the harmony search optimization algorithm aimed to find the optimum combination of states of decision variables that maximizes the short and long-term social contribution according to the code of the decision-making model (Fig. 6). Sub-section 4.3 explains the steps followed to find the optimal projects (i.e. projects with greater social contribution in the short and long term simultaneously). The algorithm parameters were selected according to the experimental design methodology proposed by García-Segura et al. (2015). Furthermore, IWI was adjusted by stopping the procedure when the convergence criterion was achieved. The recommended calibration: HMS $=200$, $\mathrm{HMCR}=0.7, \mathrm{PAR}=0.4$, and $\mathrm{IWI}=50000$. According to the principle of non-inferior alternatives, a set of projects was ranked.

Fig. 8a shows the set of project alternatives that define the social contribution limit, which are integrated by non-inferior alternative of road projects or close to them. In light of the foregoing, Fig. 8b shows a ranking of $1^{\text {st }}, 2^{\text {nd }}$ and $3^{\text {rd }}$ place for the road project set. In this instance, the alternative set is composed of 47 alternatives in $1^{\text {st }}$ place (non-inferior), 45 alternatives in $2^{\text {nd }}$ place, and 49 alternatives in $3^{\text {rd }}$ place. Considering the number of preselected road projects, Fig. 8c represents the social contribution mean of each one. Finally, Table 5 shows the values of decision variables that represent the 20 road project alternatives with the highest social contribution mean $(>5.5)$. Thus, the decision variables tend toward long-term social contribution according to the model set. From the analysis of Table 5, alternatives 9 and 18 present the least short-term social contribution. Some states of decision variables can explain this situation, for example, the low commerce index in the area (D5), the low impact of type of road (D16) or the low connectivity with more developed towns (D20). By contrast, a high social contribution in the long-term is feasible given the low school attendance (D4), the low access to health professionals (D3) and the adequate performance of infrastructure variables (e.g. $D 2, D 8, D 10, D 12)$. The last one is only feasible provided there 
are health-care and education centers in the area. It is worth noting that while some decision variables $(D 1-D 3, D 6, D 8-D 13, D 15, D 17-D 19, D 21)$ must take the same value, others $(D 4$, $D 5, D 7, D 14, D 16, D 20)$ must adjust their values to achieve short and long-term social sustainability maximization.

a)

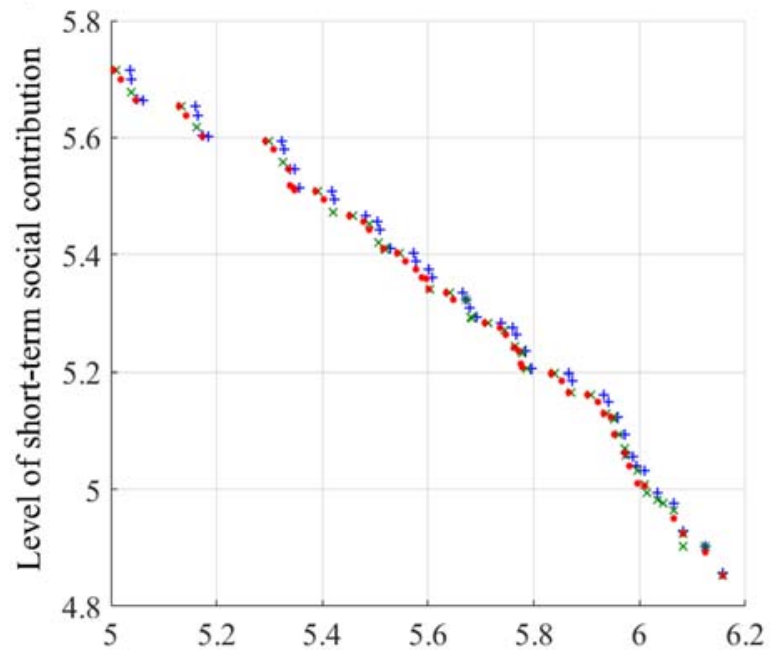

b)

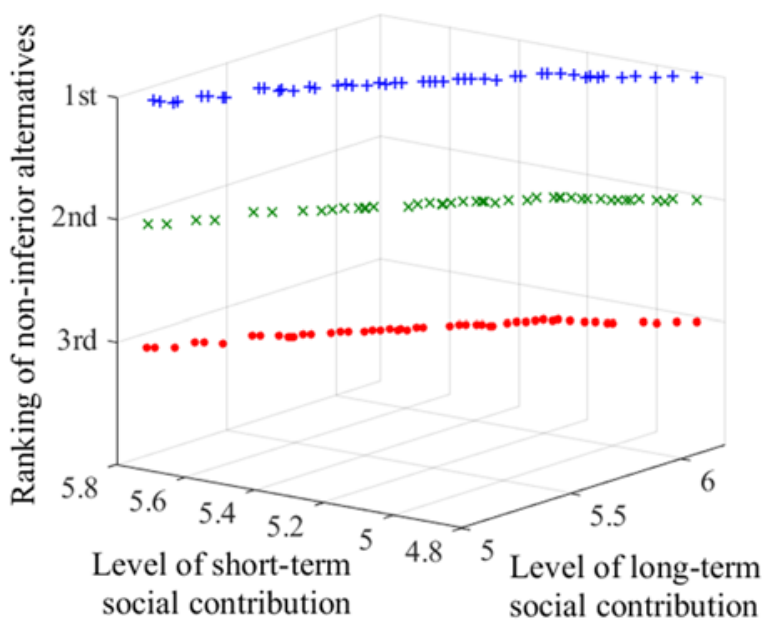

Level of long-term social contribution

c)

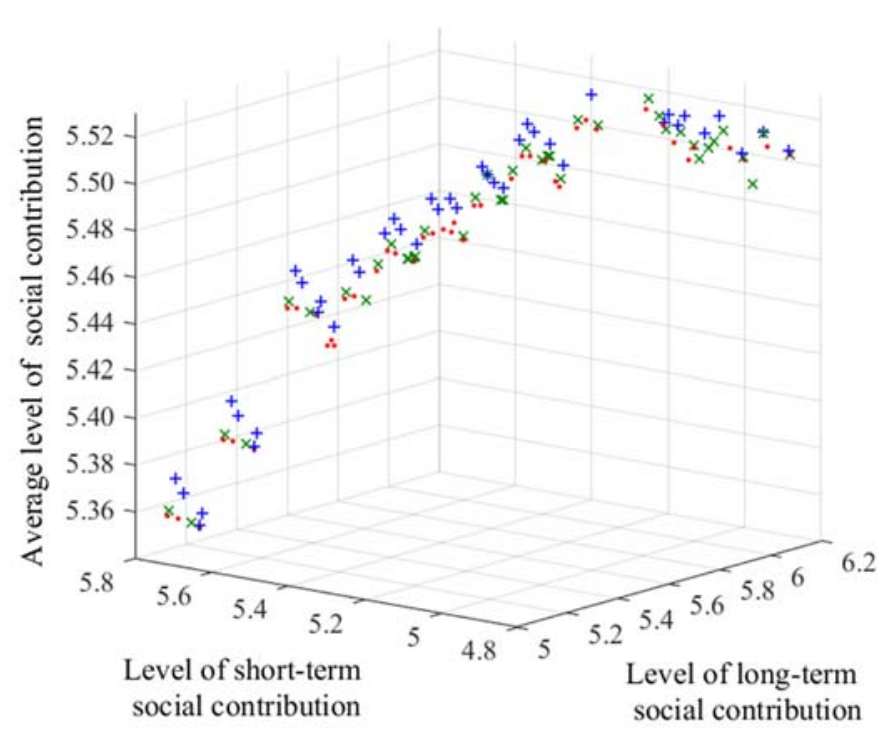

+47 non-inferior alternatives

$\times \quad 45$ alternatives in 2 nd place

- 49 alternatives in 3rd place

Fig. 8. Analysis of eligible alternatives: (a) social contribution limit, (b) ranking of noninferior alternatives, (c) behavior of the social contribution mean 
Table 5. Sample of non-inferior alternatives with a higher social contribution mean

\begin{tabular}{|c|c|c|c|c|c|c|c|c|c|c|c|c|c|c|c|c|c|c|c|c|c|c|c|c|}
\hline \multirow[t]{2}{*}{$\mathrm{N}^{\circ}$} & \multicolumn{3}{|c|}{ Social contribution level } & \multicolumn{21}{|c|}{ States of each decision variable (D) } \\
\hline & ST & LT & Mean & 1 & 2 & 3 & 4 & 5 & 6 & 7 & 8 & 9 & 10 & 11 & 12 & 13 & 14 & 15 & 16 & 17 & 18 & 19 & 20 & 21 \\
\hline 1 & 5.162 & 3 & 47 & 2 & 4 & 3 & 3 & 1 & 1 & 1 & 3 & 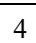 & 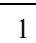 & 2 & 2 & 1 & 1 & 1 & 3 & 1 & 2 & 3 & 1 & 3 \\
\hline 2 & 150 & 5.940 & 5.545 & 4 & 4 & 3 & 3 & 1 & 1 & 1 & 3 & 4 & 1 & 2 & 2 & 1 & 1 & 1 & 2 & 1 & 2 & 3 & 1 & 3 \\
\hline 3 & 5.123 & 5.959 & 5.541 & 2 & 4 & 3 & 3 & 1 & 1 & 1 & 3 & 4 & - & 2 & 2 & 1 & 1 & 1 & 1 & 1 & 2 & 3 & 1 & 3 \\
\hline 4 & 5.095 & 5.971 & 5.533 & 2 & 4 & 3 & 3 & - & 1 & 1 & 3 & 4 & 1 & 2 & 2 & 1 & 1 & 1 & 3 & 1 & 2 & 3 & 1 & 3 \\
\hline 5 & 5.198 & 5.866 & 5.532 & 2 & 4 & 3 & 2 & 1 & 1 & 1 & 3 & 4 & 1 & 2 & 2 & 1 & 1 & 1 & 3 & 1 & 2 & 3 & 1 & 3 \\
\hline 6 & 86 & 5.873 & 5.529 & 2 & 4 & 3 & 2 & 1 & 1 & 1 & 3 & 4 & 1 & 2 & 2 & 1 & 1 & 1 & 2 & 1 & 2 & 3 & 1 & 3 \\
\hline 7 & 5.056 & 5.986 & 5.521 & 2 & 4 & 3 & 3 & 2 & 1 & 1 & 3 & 4 & 1 & 2 & 2 & 1 & 1 & 1 & 2 & 1 & 2 & 3 & 2 & 3 \\
\hline 8 & 5.032 & 6.009 & 5.521 & 2 & 4 & 3 & 3 & 2 & 1 & 1 & 3 & 4 & 1 & 2 & 2 & 1 & 1 & 1 & 1 & 1 & 2 & 3 & 2 & 3 \\
\hline 9 & 76 & 6.064 & 5.520 & 2 & 4 & 3 & 3 & 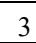 & 1 & 1 & 3 & 4 & 1 & 2 & 2 & 1 & 1 & 1 & 1 & 1 & 2 & 3 & 2 & 3 \\
\hline 10 & 51 & 5.974 & 5.518 & 2 & 4 & 3 & 3 & 1 & 1 & 1 & 3 & 4 & 1 & 2 & 2 & 1 & 1 & 1 & 1 & 1 & 2 & 3 & 2 & 3 \\
\hline 11 & 5 & 5.7 & 8 & 2 & 4 & 3 & 1 & 1 & 1 & 1 & 3 & 4 & 1 & 2 & 2 & 1 & 1 & 1 & 3 & 1 & 2 & 3 & 1 & 3 \\
\hline 12 & 39 & 5.994 & 5.517 & 2 & 4 & 3 & 3 & 3 & 1 & 1 & 3 & 4 & 1 & 2 & 2 & 1 & 1 & 1 & 1 & 1 & 2 & 3 & 1 & 3 \\
\hline 13 & 5.263 & 5.766 & 5. & 2 & 4 & 3 & 1 & 1 & 1 & 1 & 3 & 4 & 1 & 2 & 2 & 1 & 1 & 1 & 2 & 1 & 2 & 3 & 1 & 3 \\
\hline 14 & 903 & 6.124 & 4 & 2 & 4 & 3 & 3 & 3 & 1 & 1 & 3 & 4 & 1 & 2 & 2 & 1 & 1 & 1 & 1 & 1 & 2 & 3 & 3 & 3 \\
\hline 15 & 4.994 & 6.033 & 5 & 2 & 4 & 3 & 3 & 3 & 1 & 1 & 3 & 4 & 1 & 2 & 2 & 1 & 1 & 1 & 2 & 1 & 2 & 3 & 2 & 3 \\
\hline 16 & 84 & 5.7 & 1 & 2 & 4 & 3 & 3 & 1 & 1 & 2 & 3 & 4 & 1 & 2 & 2 & 1 & 1 & 1 & 3 & 1 & 2 & 3 & 1 & 3 \\
\hline 17 & 5.234 & 5.785 & 5.510 & 2 & 4 & 3 & 1 & 1 & 1 & 1 & 3 & 4 & 1 & 2 & 2 & 1 & 1 & 1 & 1 & 1 & 2 & 3 & 1 & 3 \\
\hline 18 & 4.857 & 6.15 & & 2 & 4 & 3 & 3 & 4 & 1 & 1 & 3 & 4 & 1 & 2 & 2 & 1 & 1 & 1 & 1 & 1 & 2 & 3 & 3 & 3 \\
\hline 19 & 4.929 & 6.082 & 5.506 & 2 & 4 & 3 & 3 & 4 & 1 & 1 & 3 & 4 & 1 & 2 & 2 & 1 & 1 & 1 & 1 & 1 & 2 & 3 & 2 & 3 \\
\hline 20 & 5.205 & 5.796 & 5.501 & 2 & 4 & 3 & 1 & 2 & 1 & 1 & 3 & 4 & 1 & 2 & 2 & 1 & 1 & 1 & 1 & 1 & 2 & 3 & 1 & 3 \\
\hline 21 & 5.335 & 5.666 & 5.500 & 2 & 4 & 3 & 3 & 1 & 1 & 1 & 3 & 4 & 1 & 2 & 2 & 1 & 3 & 1 & 3 & 1 & 2 & 3 & 1 & 3 \\
\hline
\end{tabular}

Thus, an example of a real project alternative is described in Table 6. The characteristics of this alternative coincide with the decision variables of option number 4 (Table 5). The project consists of the improvement of a road $(7.5 \mathrm{~km})$ that links the departmental capital of La Union (pop. 34045) and the localities of Las Playitas (set of poor populations and beaches). The location of this alternative can be georeferenced at $13^{\circ} 16^{\prime} 49.91^{\prime \prime} \mathrm{N}, 87^{\circ} 47^{\prime} 36.44^{\prime \prime} \mathrm{W}$ (start of project) and $13^{\circ} 19^{\prime} 50.49^{\prime \prime} \mathrm{N}, 87^{\circ} 49^{\prime} 30.78^{\prime \prime} \mathrm{W}$ (end of project). The example differentiates the context and the design-planning proposal.

Table 6. Example of the characterization of a socially sustainable project alternative

\begin{tabular}{|l|l|}
\hline & Description of the road improvement project La Union - Las Playitas, El Salvador \\
\hline & $\begin{array}{l}\text { In the macrozone the opening of the new port of La Union is expected. The construction of the port generated } \\
\text { greater private investment and sales indices of }+21 \% \text {. However, the value of the properties of the area of influence } \\
\text { does not exceed } 30 \% \text { of the range of values of the southern departmental zone. } \\
\text { It has a heavily deteriorated gravel road without lighting. The traffic of private vehicles that access the beaches from } \\
\text { the city increases in the summer. In } 2014 \text { there were } 11 \text { deaths due to vehicle accidents. }\end{array}$ \\
$\begin{array}{l}\text { Currently, the area has two daily bus services, except during the winter season, when access is interrupted by } \\
\text { flooding. The rural population does not easily access the primary health center. More than } 50 \% \text { of the active } \\
\text { population in the area of influence participates in fishing committees, artisan groups, churches, housing committees } \\
\text { and a participatory paving group. Most employment in the area of influence is informal and the unemployment rate } \\
\text { exceeds } 30 \% \text {. There is no background of archeological findings or indigenous population in the area. } \\
\text { Two elementary schools are located along the side of the road. School attendance is not consistent; in winter } \\
\text { attendance reaches 30\%. }\end{array}$ \\
\hline 0
\end{tabular}




\begin{tabular}{|c|c|}
\hline & Description of the road improvement project La Union - Las Playitas, El Salvador \\
\hline 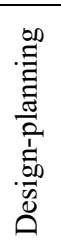 & $\begin{array}{l}\text { The improvement project connects with the bypass to the port of La Union and the roundabout to access the city } \\
\text { The width of the road allows the improvement without affecting the adjoining properties. The improvement consists } \\
\text { of a hydraulic concrete pavement } 15 \mathrm{~cm} \text { thick, } 7 \mathrm{~m} \text { wide, with two tracks and a useful life of } 20 \text { years. In addition, it } \\
\text { includes bays for bus stops in populated areas and } 4 \mathrm{~km} \text { of bike paths. The installation of containment barriers, } \\
\text { speed reducers and signaling necessary is also included. For the construction, hiring workers from the area is } \\
\text { considered. Information signs and identification of local areas will be handcrafted according to the character of the } \\
\text { area. The road lavout integrates the connections for } 18 \text { locations. }\end{array}$ \\
\hline
\end{tabular}

\section{DISCUSSION}

Each alternative is a combination of states of 21 decision variables representing the road characteristics and location context. Table 5 identifies project alternatives with greater social contribution simultaneously in the short and long term; i.e., the method obtained road characteristics more compatible with some context conditions. Furthermore, according to the model configuration, certain decision variables are more sensitive (Mel et al., 2015). For example, the variable D16 "Type of road" or D4 "School attendance in the zone" have greater variability according to the state of the remaining variables.

Stages 1 and 2 of this method were used to model and evaluate the social contribution of a road project. Through Stage 3, alternatives of infrastructure projects were estimated to support the planning process and the decision-making from the social viewpoint. Operationally, Bayesian reasoning techniques and the Noisy-OR model have given functionality to the decision-making model. With these techniques the uncertainty of variables was treated according to the experts' experience (Chen and Pollino, 2012; Mkrtchyan et al., 2016). Moreover, a multi-objective approach allowed dealt with opposing aspects of the assessment (Yepes et al., 2015). In this case, short-term social welfare does not always contribute to equitable development in the long-term (Mostafa and El-Gohary, 2014). In particular, the roads located in contexts with weak states of decision variables are more likely to have a high long-term social contribution. Conversely, favorable current states of the decision variables are more likely to have a high short-term social contribution.

The proposed method can be replicated in any geographic context and type of infrastructure. For this, an appropriate set of experts with experience in the study area and geographic context must be selected. Furthermore, the variables, their states and relationships of the model must adapt to the conditions of the context and type of infrastructure. This means that each context and infrastructure type will require a new decision-making model. Thus, in all cases the alternative locations must share similar development strategies to be evaluated under the same decision-making model. Moreover, the correct determination of the conditional probability tables is a laborious but necessary task for the method to work. This method does not take synergy and interference between causes into consideration. Additional questions put to the experts and a more complex formulation of the Bayesian network using a recursive Noisy-OR (Lemmer and Gossink, 2004) should be required for this. All these considerations are needed to guarantee an appropriate interpretation of the results.

The prioritization of infrastructure projects from a social sustainability viewpoint can support the political and strategic decisions in a region. In this sense, the method promotes the systematic participation of experts and the agreement to build a knowledge-based system. 
Aspects such as learning capacity, self-organization, diversity, trust and common sense are key elements to promote social sustainability through participatory models (Missimer et al., 2017). Thus, the method establishes a decision-making model which is adjustable over time according to a society's needs.

\section{CONCLUSIONS}

This paper proposes a method to optimize infrastructure projects alternatives and their location contexts from the social sustainability point of view. This method emphasizes the interaction between the infrastructure and the contextual conditions to estimate the infrastructure's short and long-term social contribution in three stages: preparation of the decision-making model through Delphi technique, formulation of the model using the Bayesian reasoning method and a multi-objective optimization process.

The method was applied in a real context for the prioritization of potential infrastructure projects of roads in various geographic areas of El Salvador. The implementation of the method made it possible to distinguish the contributions of different road projects to social sustainability. An alternative was represented through a specific combination of characteristics of planning, design and location context. Additionally, this methodology allowed the experience in the context and the uncertainty of the decision-making to be taken into account. The discussion stages also promoted the social learning of different sectors in a structured way. Moreover, opposite approaches that derive of the same decision variables were able interact in a single model. Bayesian reasoning allows the processing of the different aspects that influence the social contribution. Thus, it was possible to classify in degrees of priority the best set of alternatives of infrastructure projects with simultaneous short and longterm social contributions. This approach gives a tool to select the strategic necessities of a region. However, it is worth noting that an adequate implementation of the method requires a decision-making model consistent with experts' experience of the infrastructure type and the context. Thus, the characteristics of alternative locations must be consistent with the states of decision variables in the model. Furthermore, the independence of the definition of decision variables and criteria allow the implementation of Noise-OR in the Bayesian reasoning.

This proposal supports early decision-making to prioritize and determine the characteristics of an infrastructure project from the point of view of social sustainability. It is a support tool for public entities to formulate and prioritize investment in infrastructure. The method promotes experts' participation to build a knowledge-based evaluation system. This way, the method can be aligned with a region's development strategies.

The results of this method can be complemented with assessments of the economic and environmental dimension of sustainability. Thus, it can also be replicated in any geographic context and type of infrastructure once the elements of the decision network have been adapted. In the future, this proposal could integrate all the elements of sustainability, taking into account the conditions of synergy and interference between causes. 


\section{ACKNOWLEDGMENTS}

This research was funded by the Government of Chile under the Doctoral Fellowship Abroad Program (grant CONICYT-2015/72160059) and the Spanish Ministry of Economy and Competitiveness along with FEDER funding (project BIA2014-56574-R). The authors are grateful to both the United Nations Development Programme and the Ministry of Public Works, Transportation, Housing and Urban Development of El Salvador for their participation in the implementation of the proposed method (Project 00074250).

\section{REFERENCES}

Alshubbak, A., Pellicer, E., Catalá, J., Teixeira, J.C., 2015. A model for identifying owner's needs in the building life cycle. J. Civ. Eng. Manag. 21, 1-15. doi: $10.3846 / 13923730.2015 .1027257$

Benoit-Norris, C., Cavan, D.A., Norris, G., 2012. Identifying social impacts in product supply chains: Overview and application of the social hotspot database. Sustainability 4, 19461965. doi:10.3390/su4091946

Bertone, E., Sahin, O., Richards, R., Roiko, A., 2016. Extreme events, water quality and health: A participatory Bayesian risk assessment tool for managers of reservoirs. J. Clean. Prod. 135, 657-667. doi: 10.1016/ j.jclepro.2016.06.158

Bueno, P.C., Vassallo, J.M., Cheung, K., 2015. Sustainability Assessment of Transport Infrastructure Projects: A Review of Existing Tools and Methods. Transp. Rev. 35, 622649. doi:10.1080/01441647.2015.1041435

Carvalho, P., Marques, R.C., 2016. Estimating size and scope economies in the Portuguese water sector using the Bayesian stochastic frontier analysis. Sci. Total Environ. 544, 574-586. doi:10.1016/j.scitotenv.2015.11.169

Celio, E., Koellner, T., Grêt-Regamey, A., 2014. Modeling land use decisions with Bayesian networks: Spatially explicit analysis of driving forces on land use change. Environ. Model. Softw. 52, 222-233. doi:10.1016/j.envsoft.2013.10.014

Chen, S.H., Pollino, C.A., 2012., Good practice in Bayesian network modelling. Environ. Model. Softw. 37, 134-145. doi: 10.1016/j.envsoft.2012.03.012

Chhipi-Shrestha, G.K., Hewage, K., Sadiq, R., 2015. "Socializing” sustainability: a critical review on current development status of social life cycle impact assessment method. Clean Technol. Environ. Policy 17, 579-596. doi:10.1007/s10098-014-0841-5

Colantonio, A., 2011. Social sustainability: exploring the linkages between research, policy and practice. European Research on Sustainable Development, 1, 35-57. doi: 10.1007/978-3-642-19202-9_5

Cortés J.M., Pellicer E., Catalá J., 2012. Integration of occupational risk prevention courses in engineering degree: Delphi study. J. Prof. Issues Eng. Educ. Pract.138, 31-36. doi: 10.1061/(ASCE)EI.1943-5541.0000076

Delgado, A., Romero, I., 2016. Environmental conflict analysis using an integrated grey clustering and entropy-weight method: A case study of a mining project in Peru. Environ. Model. Softw. 77, 108-121. doi: 10.1016 / j.envsoft.2015.12.011

Dendena, B., Corsi, S., 2015. The Environmental and Social Impact Assessment: a further step towards an integrated assessment. J. Clean. Prod. 108, 965-977. doi: 10.1016/j.jclepro.2015.07.110

Diez, F.J., Druzdzel, M.J., 2007. Canonical Probabilistic Models for Knowledge Engineering, Technical Report CISIAD-06-01. Madrid, Spain. 
DIGESTYC- Dirección General de Estadísticas y Censos, 2015. Encuesta de hogares de propósitos múltiples. San Salvador, El Salvador.

Dorner, S., Shi, J., Swayne, D., 2007. Multi-objective modelling and decision support using a Bayesian network approximation to a non-point source pollution model. Environ. Model. Softw. 22, 211-222. doi:10.1016/j.envsoft.2005.07.020

Egre D., Senecal P., 2003. Social impact assessments of large dams throughout the world: Lessons learned over two decades. Impact. Assess. Project Appraisal 21, 215-224. doi: $10.3152 / 147154603781766310$

Foth, N., Manaugh, K., El-Geneidy, A. M., 2013. Towards equitable transit: examining transit accessibility and social need in Toronto, Canada, 1996-2006. J. Transp. Geogr. 29, 1-10. doi: 10.1016/j.jtrangeo.2012.12.008.

Fulford, R.S., Smith, L.M., Harwell, M., Dantin, D., Russell, M., Harvey, J., 2015. Human well-being differs by community type: Toward reference points in a human well-being indicator useful for decision support. Ecol. Indic. 56, 194-204. doi:10.1016/j.ecolind.2015.04.003

Gannon, C. A., Liu, Z., (1997). Poverty and Transport (No. TWU-30), World Bank, Washington, DC.

García-Segura, T., Yepes, V. 2016. Multiobjective optimization of post-tensioned concrete box-girder road bridges considering cost, CO2 emissions, and safety. Eng. Struct. 125, 325-336. doi: 10.1016/j.engstruct.2016.07.012.

Geem, Z.W., Kim, J.H., Loganathan, G. V., 2001. A new heuristic optimization algorithm: Harmony search. Simulation. 76, 60-68. doi: 10.1177/003754970107600201

Gervásio, H., Simoes da Silva. L., 2012. A probabilistic decision-making approach for the sustainable assessment of infrastructures. Expert Syst. Appl. 39, 7121-7131. doi: 10.1016/j.eswa.2012.01.032

Hallowell M., Gambatese, J., 2010. Application of the Delphi method to CEM research. J. Constr. Eng. Manage.136, 99-107. doi:10.1061/(ASCE)CO.1943-7862.0000137

Jato-Espino, D., Castillo-Lopez, E., Rodriguez-Hernandez, J., Canteras-Jordana, J.C., 2014. A review of application of multi-criteria decision making methods in construction. Autom. Constr. 45, 151-162. doi:10.1016/j.autcon.2014.05.013

Labuschagne, C., Brent, A.C., van Erck, R.P.G., 2005. Assessing the sustainability performance of industries. J. Clean. Prod. 13(4), 373-385. doi: 10.1016/j.jclepro.2003.10.007.

Lemmer, J. F., Gossink, D. E., 2004. Recursive Noisy OR- A ruler for estimating complex probabilistic interactions. IEEE T. Syst. Man Cyb. 34, 2252-2261. doi: 10.1109/TSMCB.2004.834424

Lo, S., Ma, H., Lo, S., 2005. Quantifying and reducing uncertainty in life cycle assessment using the Bayesian Monte Carlo method. Sci. Total Environ. 340, 23-33. doi:10.1016/j.scitotenv.2004.08.020

Mel, J., Gómez, D., de la Cruz, P., 2015. Análisis de sensibilidad y estudio crítico del modelo de evaluación de la sostenibilidad de la Instrucción Española de Hormigón Estructural. Inf. Const. 67. doi: 10.3989/ic.14.126

Mkrtchyan, L., Podofillini, L., Dang, V.N., 2016. Methods for building conditional probability tables of Bayesian belief networks from limited judgment: An evaluation for human reliability application. Reliab. Eng. Syst. Saf. 151, 93-112. doi: 10.1016/j.ress.2016.01.004

Missimer, M., Robèrt, K-H., Broman, G., 2017. A strategic approach to social sustainability Part 1: exploring the social system. J. Clean. Prod. 140, 32-41. doi: 10.1016/j.jclepro.2016.03.170 
Mostafa, M., El-Gohary, N., 2014. Stakeholder-sensitive social welfare-oriented benefit analysis for sustainable infrastructure project development, J. Constr. Eng. Manage. 140, 04014038. doi: 10.1061/(ASCE)CO.1943-7862.0000788

Munda, G., 2004. Social multi-criteria evaluation: Methodological foundations and operational consequences. Eur. J. Oper. Res. 158, 662-677. doi:10.1016/S03772217(03)00369-2

Munda, G., 2006. Social multi-criteria evaluation for urban sustainability policies. Land use policy 23, 86-94. doi:10.1016/j.landusepol.2004.08.012

Pellicer, E., Sierra, L., Yepes, V., 2016. Appraisal of infrastructure sustainability by graduate students using an active-learning method, J. Clean. Prod. 113, 884-896. doi:10.1016/j.jclepro.2015.11.010

Pearl, J., 2009. Causality: Models, Reasoning and Inference, 2nd Ed. Cambridge University Press, Cambridge.

Ricart, J., Hüttemann, G., Lima, J., Barán, B., 2011. Multiobjective harmony search algorithm proposals, Electron. Notes Theor. Comput. Sci. 281, 51-67. doi:10.1016/j.entcs.2011.11.025.

Schwarz, N., Flacke, J., Sliuzas, R., 2016. Modelling the impacts of urban upgrading on population dynamics. Environ. Model. Softw. 78, 150-162. doi: 10.1016/j.envsoft.2015.12.009

Sierra, L., Pellicer, E., Yepes, V., 2016. Social sustainability in the life cycle of Chilean public infrastructure. J. Constr. Eng. Manage. 142, 05015020. doi: 10.1061/(ASCE)CO.1943-7862.0001099

Sierra, L., Pellicer, E., Yepes, V., 2017a. Method for estimating the social sustainability of infrastructure projects. Environ. Impact Assess. Rev. 65, 41-53. doi:10.1016/j.eiar.2017.02.004

Sierra, L., Yepes, V., Pellicer, E., 2017b. Assessing the social sustainability contribution of an infrastructure project under conditions of uncertainty. Environ. Impact Assess. Rev. 67, 61-72. doi:10.1016/j.eiar.2017.08.003

Soltani, A., Hewage, K., Reza, B., Sadiq, R. 2015. Multiple stakeholders in multi-criteria decision-making in the context of Municipal Solid Waste Management: A review. Waste Manag. 35, 318-328. doi:10.1016/j.wasman.2014.09.010

Torres-Machi, C., Chamorro, A., Pellicer, E., Yepes, V., Videla, C., 2015. Sustainable pavement management: Integrating economic, technical and environmental aspects in decision making. Transport. Res. Rec. 2523, 56-63. doi: 10.3141/2523-07

UNDP-United Nations Development Programme, 2013. Informe sobre Desarrollo Humano E1 Salvador 2013. Imaginar un nuevo país. Hacerlo posible. Diagnóstico y propuesta. San Salvador, El Salvador.

Valdés-Vásquez, R., Klotz L.E., 2013. Social sustainability considerations during planning and design: framework of processes for construction projects, J. Constr. Eng. Manage. 139, 80-89. doi: 10.1061/(ASCE)CO.1943-7862.0000566

Vanclay, F., 2002. Conceptualising social impacts. Environ. Impact Assess. 22, 183-211. doi: 10.1016/S0195-9255(01)00105-6

van Haaster, B., Ciroth, A., Fontes, J., Wood, R., Ramirez, A., 2016. Development of a methodological framework for social life-cycle assessment of novel technologies. Int. J. Life Cycle Assess. 22, 423-440. doi:10.1007/s11367-016-1162-1

WCED -World Commission on Environment and Development, 1987. Our Common Future. Oxford University Press, Oxford, United Kingdom.

Wikimedia Commons [WWW Document], 2007. URL https://commons.wikimedia.org/wiki/File:Departments_of_El_Salvador_named.svg. 
Xu, H., Gao, X.Z., Wang, T., Xue, K., 2010. Recent Advances in Harmony Search Algorithm, in: Z.W. Geem (Ed.), Springer Berlin Heidelberg, Berlin, 11-22. doi:10.1007/978-3-64204317-8 2

Yadollahi, M., Ansari, R., Majid, M. Z. A., Yin C.H., 2015. A multi-criteria analysis for bridge sustainability assessment: a case study of Penang Second Bridge, Malaysia. Struct. Infrastruct. Eng. 11, 638-654. doi:10.1080/15732479.2014.893002

Yepes, V.,Garcia-Segura, T., Moreno-Jimenez, J.M., 2015. A cognitive approach for the multi-objective optimization of RC structural problems. Arch. Civil Mech. Eng. 15, 10241036. doi: 10.1016/j.acme.2015.05.001

Zastrow, P., Molina-Moreno, F., Garcia-Segura, T., Martí, J., Yepes, V., 2017. Life cycle assessment of cost-optimized buttress earth-retaining walls: a parametric study. J. Clean. Prod. 140,1037-1048. doi: 10.1016/j.jclepro.2016.10.085 